\title{
Two extraordinary troglobitic species of Allokoenenia (Eukoeneniidae: Palpigradi) from Brazil: first records of this initially monotypic genus more than a century after its description
}

\author{
Maysa Fernanda Villela Rezende SOUZA ${ }^{\circledR 1,{ }^{*}}$ \& Rodrigo Lopes FERREIRA ${ }^{\left({ }_{2}\right.}$ \\ ${ }^{1,2}$ Centro de Estudos em Biologia Subterrânea, Departamento de Ecologia e Conservação, \\ Universidade Federal de Lavras, Lavras, MG. CEP 37200-000, Brazil. \\ ${ }^{*}$ Corresponding author: mvillelabio@yahoo.com.br \\ 22Email: drops@ufla.br \\ ${ }^{1}$ urn:1sid:zoobank.org:author:5FB1C9A2-5F8A-4859-8749-71B23E95C6A0 \\ ${ }^{2}$ urn:lsid:zoobank.org:author:139F3313-234C-41B2-A698-F1189F4318D2
}

\begin{abstract}
The diversity of Palpigradi is not evenly distributed among its different branches. The widespread genus Eukoenenia includes $80 \%$ of the species, while the other genera are poorly known. Allokoenenia certainly is the most understudied genus because it is represented only by the African species Allokoenenia afra Silvestri, 1913. Its description is short and does not include many features depicted in modern taxonomy of Palpigradi. In this paper, we describe two troglobitic species of Allokoenenia, report the occurrence of a third species represented by an immature specimen from Brazilian caves, and provide brief notes on the morphology of A. afra. Allokoenenia canhembora sp. nov., A. stygia sp. nov., and Allokoenenia sp. differ from A. afra by several morphological features, including more elongated appendages and a greater number of blades on lateral organs. Thus, they are considered troglomorphic. These new species are vulnerable to extinction because they are endemic to a single or few caves directly impacted by mining activities and groundwater exploitation. This study represents the first step for the conservation of these species and their habitats, since Brazilian caves with rare troglobites cannot be irreversibly impacted. Also, it brings important contributions on the distribution and morphology of this enigmatic genus.
\end{abstract}

Keywords. Taxonomy, morphology, cave-dwellers, troglomorphism, conservation.

Souza M.F.V.R. \& Ferreira R.L. 2022. Two extraordinary troglobitic species of Allokoenenia (Eukoeneniidae: Palpigradi) from Brazil: first records of the genus after its description. European Journal of Taxonomy 789: 11-48. https://doi.org/10.5852/ejt.2022.789.1627

\section{Introduction}

Palpigradi Thorell, 1888 was the last described order of Arachnida, with the description of the first species, Eukoenenia mirabilis Grassi \& Calandruccio, 1885. Even more than one century after their 
discovery, these arachnids are often referred to as enigmatic (e.g., Harvey 2002; Souza \& Ferreira 2013; Giribet et al. 2014; Ballesteros et al. 2019) because they are represented only by 116 living species and many of their biological aspects remain obscure. Furthermore, many taxa are known based on a single or few specimens and remain so even several years after their description (Christian et al. 2014; Souza et al. 2020).

Palpigradi currently includes two families. The representatives of Prokoeneniidae Condé, 1996 and Eukoeneniidae Petrunkevitch, 1955 can be distinguished by the presence, in the formers, of ventral sacs on the opisthosomal sternites IV-VI (Harvey 2003). The Eukoenenian lineage is represented by four genera, including Eukoenenia Börner, 1901, which is the most diverse genus of palpigrades, with 93 named species (Harvey 2003; Souza et al. 2020; Bu et al. 2021). At the same time, it also comprises the monotypic genus Allokoenenia Silvestri, 1913, which is considered one of the most understudied taxa within Palpigradi because it is represented only by the three type specimens (two adult females and one immature) of Allokoenenia afra Silvetri, 1913 from Guinea, West Africa (Condé 1992). Furthermore, the short description of this species was published more than a century ago, and thus it does not conform to the modern taxonomy of Palpigradi. Condé (1992) provisionally assigned two cave-dwelling immature specimens from Thailand to Allokoenenia due to the shape of the last opisthosomal segments and the flagellum. He described their morphology, but the specimens were not formally named, being considered of uncertain taxonomic position. Therefore, in spite of the long time since the description of $A$. afra, no additional species have been discovered.

According to Rowland \& Sissom (1980), the representatives of the genus Allokoenenia can be recognized by the following features: ninth and eleventh abdominal segments equal in width, half as wide as eighth segment and wider than tenth segment; pygidium not greatly narrowed posteriorly; flagellum shorter than opisthosoma and with moniliform segments (segments approximately uniform in size and spherical in shape). Some palpigrades collected in Brazilian caves present the relative width of the last opisthosomal segments as described by Rowland \& Sissom (1980), which results in an appearance of the opisthosoma very similar to that illustrated by Silvestri (1913: 277, fig. VII), in the description of A. afra. The flagellum of one of these species, preserved during the collection, is shorter than the opisthosoma and have moniliform segments, also in agreement with the diagnosis of this genus. Accordingly, in this study, we describe two new species of Allokoenenia based on cave-dwelling specimens from Northeastern and Northern Brazil, which represent the first formal records of the genus after its description. Furthermore, as the species herein described have elongated appendages compared to A. afra, as well as an increased number of blades on lateral organs, they can be considered the first troglobitic species of this group. We also report the occurrence and describe the morphology of a third Brazilian species of this genus based on an immature specimen and present brief notes on the morphology of Allokoenenia afra obtained from the study of the type specimens.

\section{Material and methods}

The individuals were found through visual search inside the different caves, captured with the aid of a fine brush and fixed and stored in vials with 70\% ethanol. In the laboratory, all the type specimens were cleared in Nesbitt's solution and mounted individually in microscopy slides using Hoyer's medium. Subsequently, these semi-permanent slides stayed in an oven at $55^{\circ} \mathrm{C}$ for 20 days in order to dry the mounting medium. The additional specimen of Allokoenenia canhembora sp. nov. is stored in $70 \%$ ethanol and the description of this species was based on the holotype.

We studied and measured the type specimens under a Zeiss Axio Scope A1 microscope with phase contrast and differencial interference contrast. Measurements are given in micrometers. The pictures were taken with a digital camera (Axiocam 105 Colour) attached to this equipment. The specimens were illustrated under a camera lucida coupled to a Leica DM 750 microscope equipped with phase contrast. 
The specimens of Allokoenenia canhembora sp. nov. (ISLA 50394; ISLA50395) and Allokoenenia sp. (ISLA 50396) are deposited in the Collection of Subterranean Invertebrates of Lavras (ISLA), Ecology and Conservation Department, Federal University of Lavras, Lavras, Minas Gerais, and the specimens of Allokoenenia stygia sp. nov. (MZSP 54247; MZSP 54249) are deposited in the Zoology Museum of São Paulo University (MZSP), Brazil.

\section{Abbreviations for morphological terms}

The setal terminology follows Condé (e.g., Condé 1977), Christian \& Christophoryová (2013), and Mayoral \& Barranco (2017).

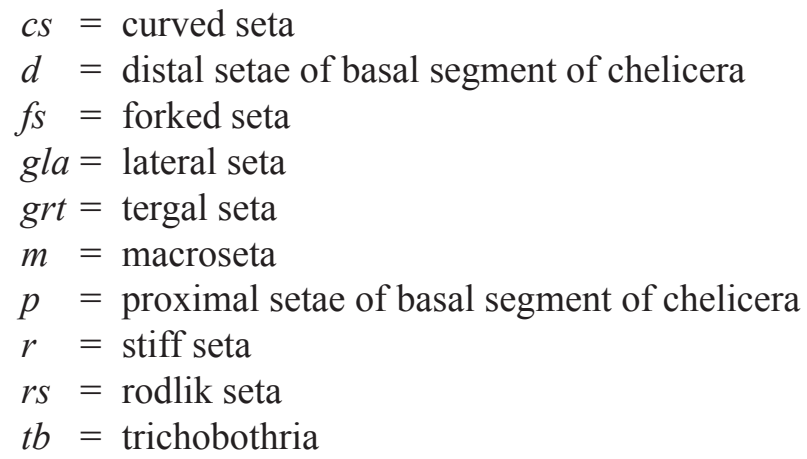

The 'long fs' present on some articles of palp and leg I are longer than the ordinary forked setae, being furcate only near the tip, similar to that described by Christian et al. (2012). The very long setae described in the flagellar segments of $A$. canhembora sp. nov. are characterized by the length greater than $100 \mu \mathrm{m}$ (it is difficult to measure them precisely because in most cases they are curved). In addition, they become thickened from their distal half and have a lanceolate tip.

We used the following abbreviations, according to Mayoral \& Barranco (2013) and Souza \& Ferreira (2018).

\begin{tabular}{|c|c|c|}
\hline$a$ & $=$ & width of the basitarsus at level of seta $r$ \\
\hline$B$ & $=$ & length of propeltidium \\
\hline B/IVbta & $=$ & ratio between lengths of prosomal shield and basitarsus IV \\
\hline bta1, bta2, bta3, bta4 & $=$ & basitarsus 1 , basitarsus 2 , basitarsus 3 , basitarsus 4 \\
\hline$c x$ & $=$ & $\operatorname{coxa}$ \\
\hline$d r, d g l a$ and $d g r t$ & $=$ & $\begin{array}{l}\text { distance between the base of the basitarsus and the insertion of seta } r, g l a \\
\text { and grt, respectively }\end{array}$ \\
\hline fe & $=$ & femur \\
\hline$L$ & $=$ & $\begin{array}{l}\text { total length of body (from the anterior margin of the propeltidium to the } \\
\text { posterior margin of the opisthosoma, without flagellum) }\end{array}$ \\
\hline$P$ & $=$ & pedipalpus \\
\hline pa & $=$ & patella \\
\hline tc & $=$ & trochanter \\
\hline $\operatorname{ta1} 1, t a 2, t a 3$ & $=$ & $\operatorname{tarsus} 1$, tarsus 2 , tarsus 3 \\
\hline$t i$ & $=$ & tibia \\
\hline Seg & $=$ & dorsal length of the basal segment of the chelicera \\
\hline I-IV & $=$ & legs I-IV \\
\hline IVbta/ti & $=$ & ratio between lengths of basitarsus IV and tibia IV \\
\hline
\end{tabular}


Table 1. Length $(\mu \mathrm{m})$ and total number of setae $(\mathrm{N})$ of the flagellar articles of Allokoenenia canhembora sp. nov. and length of the flagellar articles II-XIV of Allokoenenia afra Silvestri, 1913.

\begin{tabular}{|c|c|c|c|}
\hline \multirow[b]{2}{*}{ Article } & \multicolumn{2}{|c|}{ A. canhembora sp. nov. } & \multirow{2}{*}{$\frac{\text { A. afra Silvestri, } 1913}{\mu \mathrm{m}}$} \\
\hline & $\mu \mathrm{m}$ & $\mathbf{N}$ & \\
\hline I & 35 & 4 & - \\
\hline II & 32.5 & 2 & 20 \\
\hline III & 32.5 & 6 & 22.5 \\
\hline IV & 30 & 3 & 25 \\
\hline V & 12.5 & 5 & 17.5 \\
\hline VI & 17.5 & 2 & 22.5 \\
\hline VII & 17.5 & 5 & 22.5 \\
\hline VIII & 17.5 & 5 & 20 \\
\hline IX & 17.5 & 5 & 20 \\
\hline$X$ & 22.5 & 5 & 20 \\
\hline XI & 25 & 5 & 22.5 \\
\hline XII & 25 & 5 & 25 \\
\hline XIII & 27.5 & 5 & 22.5 \\
\hline XIV & 22.5 & 5 & 17.5 \\
\hline
\end{tabular}

The authors had access to the type specimens of Allokoenenia afra deposited at the Entomological Museum Filippo Silvestri, Department of Entomology and Agricultural Zoology of the University of Naples Federico II, Italy. The specimens are mounted in two slides: one in which there are two prosomas and one opisthosoma, as well as a detached flagellum, of adult females, and one in which there is an immature. The labels of these slides have the wording "typus" and "cotypus", respectively. Being so, the description was based on two females (one complete and one incomplete since only the prosoma remains) and one immature. Unfortunately, the specimens are in very bad condition (presenting a yellowish coloration) due to the long time they have been embedded. This means that the morphological details are no longer interpretable and only a few characters could be recognized and described. In spite of the poor preservation of the material, it was possible to take a few measurements of the adult females and these are presented in Tables 1-2. The pedipalp articles were measured from one female, and those of leg I and IV were measured from the other female since the appendages were not fully visible in the two prosomas, with exception of the basal segment of the chelicera.

\section{Results}

Class Arachnida Cuvier, 1812

Order Palpigradi Thorell, 1888

Family Eukoeneniidae Petrunkevitch, 1955

Genus Allokoenenia Silvestri, 1913

\section{Type species}

Allokoenenia afra Silvestri, 1913 by monotypy.

Allokoenenia afra Silvestri, 1913

Figs 1-2

\section{Material examined}

Typus $(+)$ and cotypus (immature)

GUINEA • Mamou. 
Table 2. Measurements and ratios of morphological characters of the three Brazilian Allokoenenia Silvestri, 1913 and the few measurements obtained from the adult females of the type series of $A$. afra Silvestri, 1913. The asterisks indicate the absence of the gla seta on basitarsus IV; the dashes indicate structures that could not be accurately measured. The body length (L) of $A$. afra was obtained from Silvestri (1913).

\begin{tabular}{|c|c|c|c|c|c|}
\hline & \multirow{2}{*}{$\frac{\text { A. canhembora sp. nov. }}{\text { ISLA } 50394}$} & \multicolumn{2}{|c|}{ A. stygia sp. nov. } & \multirow{2}{*}{$\begin{array}{c}\text { Allokoenenia sp. } \\
\text { ISLA 50396 }\end{array}$} & \multirow{2}{*}{$\frac{\text { A. afra Silvestri, } 1913}{\text { Typus }}$} \\
\hline & & MZSP 54247 & MZSP 54249 & & \\
\hline$L$ & 1420 & 1295 & 1030 & - & 1000 \\
\hline$B$ & 290 & 305 & 320 & - & - \\
\hline Seg. & 195 & 280 & 310 & 175 & $100 / 145$ \\
\hline$P c x$ & 117 & 147 & 150 & 102 & - \\
\hline Ptc & 167 & 180 & 185 & 125 & - \\
\hline Pfe & 110 & 145 & 155 & 112 & - \\
\hline$P t i$ & 142 & 165 & 167 & 117 & 90 \\
\hline Pbtal & 52 & 62 & 55 & 47 & 27 \\
\hline Pbta2 & 72 & 70 & 75 & 60 & 42 \\
\hline Ptal & 30 & 50 & 45 & 32 & 22 \\
\hline Pta2 & 37 & 50 & 47 & 37 & 22 \\
\hline Pta3 & 57 & 67 & 70 & 52 & 45 \\
\hline$I c x$ & 132 & 162 & 175 & 107 & - \\
\hline Itc & 160 & - & 147 & 137 & - \\
\hline Ife & 125 & 177 & 165 & 115 & - \\
\hline Ipa & 137 & 162 & 162 & 122 & - \\
\hline Iti & 145 & 162 & 160 & 125 & 60 \\
\hline Ibtal+2 & 125 & 137 & 132 & 112 & 55 \\
\hline Ibta3 & 87 & 70 & 72 & 75 & 23 \\
\hline Ibta $3-d r$ & 30 & 10 & 7 & 32 & - \\
\hline Ibta $3-r$ & 62 & 82 & 77 & 55 & - \\
\hline Ibta $3-a$ & 25 & 27 & 27 & 20 & - \\
\hline Ibta 3 - grt & 62 & 65 & 67 & 80 & - \\
\hline Ibta $3-d g r t$ & 12 & 20 & 22 & 20 & - \\
\hline Ibta $3 / a$ & 3.48 & 2.59 & 2.67 & 3.75 & - \\
\hline r/Ibta3 & 0.71 & 1.17 & 1.07 & 0.73 & - \\
\hline$d r / I b t a 3$ & 0.34 & 0.14 & 0.1 & 0.43 & - \\
\hline grt/Ibta3 & 0.71 & 0.93 & 0.93 & 1.07 & - \\
\hline dgrt/Ibta3 & 0.14 & 0.29 & 0.31 & 0.27 & - \\
\hline Ibta4 & 62 & 75 & 75 & 52 & 23 \\
\hline Ital & 35 & 30 & 32 & 35 & 13 \\
\hline Ita 2 & 42 & 47 & 42 & 40 & 20 \\
\hline Ita3 & 122 & 140 & 130 & 122 & 75 \\
\hline$I V c x$ & 102 & 107 & 102 & 87 & - \\
\hline$I V t c$ & 87 & 75 & 75 & 80 & - \\
\hline IVfe & 157 & 197 & 190 & 132 & - \\
\hline IVpa & 142 & 177 & 172 & 117 & - \\
\hline IVti & 155 & 162 & 147 & 137 & 67 \\
\hline IVbta & 145 & 157 & 145 & 125 & 47 \\
\hline IVbta - a & 20 & 22 & 25 & 22 & 32 \\
\hline$I V b t a-d r$ & 92 & 87 & 80 & 82 & 40 \\
\hline IVbta $-r$ & 55 & 75 & 75 & 42 & - \\
\hline IVbta - gla & $*$ & 72 & 77 & $*$ & - \\
\hline$I V-g r t$ & 62 & - & 62 & 45 & - \\
\hline$I V-d g r t$ & 45 & 55 & 47 & 40 & - \\
\hline IV - dgla & $*$ & 80 & 70 & $*$ & - \\
\hline IVbta/a & 7.25 & 7.14 & 5.8 & 5.68 & - \\
\hline IVbta/r & 2.64 & 2.09 & 1.93 & 2.98 & - \\
\hline$d r / I V b t a$ & 0.63 & 0.55 & 0.55 & 0.66 & - \\
\hline IVtal & 67.5 & 77.5 & 70 & 55 & - \\
\hline IVta 2 & 70 & 80 & 82 & 72.5 & - \\
\hline IVbta/ti & 0.94 & 0.97 & 0.99 & 0.91 & 0.7 \\
\hline$B / I V b t a$ & 2 & 1.94 & 2.21 & - & - \\
\hline
\end{tabular}



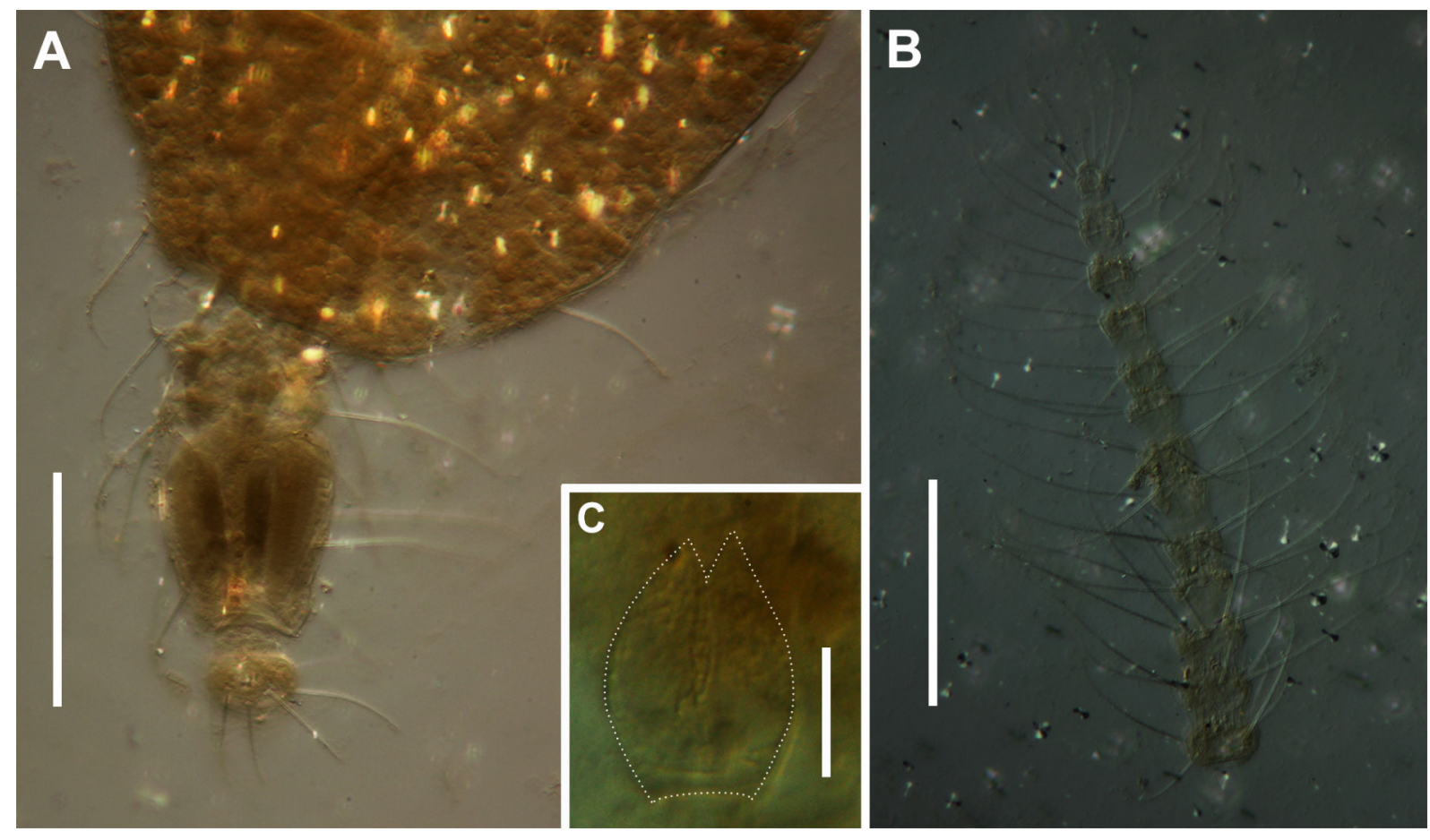

Fig. 1. Allokoenenia afra Silvestri, 1913. A. Opisthosomal segments VIII-XI and first flagellar segment, , typus. B. Flagellum (second to fourteenth flagellar segments), + , typus. C. Frontal organ, immature, cotypus. Scale bars: A-B $=100 \mu \mathrm{m} ; \mathrm{C}=10 \mu \mathrm{m}$.

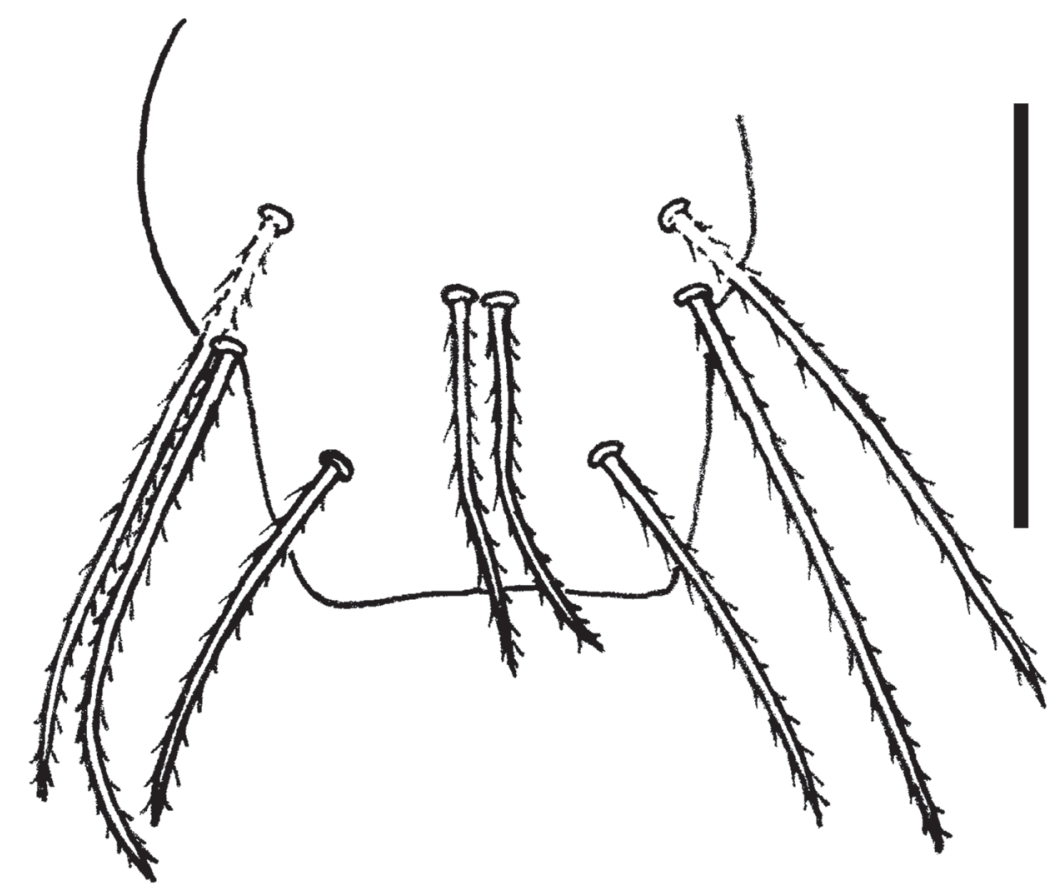

Fig. 2. Allokoenenia afra Silvestri, 1913, immature, cotypus, ventral view of opisthosomal segment XI (the insertions of the dorsal setae are represented in dashed line). Scale bar $=40 \mu \mathrm{m}$. 


\section{Description}

Measurements and Ratio. See Tables 1-2.

Adult FeMale ("typus"). Relative width of opisthosomal segments VIII-XI as described in the diagnosis of the genus by Rowland \& Sissom (1980) (Fig. 1A); last opisthosomal segment with dorsal row of $2+2$ setae inserted around its half and two pairs of ventral setae, one inserted around middle of segment and other inserted in its distal half (Fig. 2); flagellum formed by 14 short and rounded segments (Fig. 1AB), each with whorl of setae of similar shape (at least one setae smaller than others in each segment); flagellar segments 1-3, 5, 7 and 9 with apical cuticular spines.

IMMATURE SPECIMEN ("cotypus"). Frontal organ formed by two branches distally pointed and basally expanded, with fine reticulation (Fig. 1C); cheliceral fingers with 8 teeth each; 6 setae ( $g r t, r$, gla, esp and 2 esd) on basitarsus of leg IV; relative width of last opisthosomal segments and chaetotaxy of segment XI as in adult.

\section{Remarks}

As previously mentioned, the poor condition of the type material allowed us to observe and describe only a small number of morphological features. From the simple and short description of the female adult of this species provided by Silvestri (1913), which includes a few drawings, it is possible to recognize the following additional characters: lateral organ with a single blade, deutotritosternum with a single seta, and opisthosomal sternites IV-VI with three pairs of $a$ setae flanked by one $s$ seta on each side $(1 s+3 a+3 a+1 s)$. The author also described and illustrated the chaetotaxy of the genital lobes $(10+10$ and $2+2$ setae on first and second lobes respectively), and illustrated the articles of the palp, leg I and leg IV. However, it is not clear whether he represented the complete chaetotaxy of these body parts. According to the drawing of the opisthosoma presented by Silvestri (1913: 217, fig. VII, 2), the immature already has the primordia of genital lobes, but it was not possible to confirm whether it is a male or a female juvenile.

Due to the poor preservation of the type specimens, the collection of new specimens from the type locality is essential for its redescription according to the modern taxonomy of Palpigradi, thus allowing a more detailed comparison with the congeneric species.

\section{Allokoenenia canhembora sp. nov. urn:1sid:zoobank.org:act:F6B9B9E0-6B19-4FCB-82CF-A8B4F754F492}

Figs 3-9

\section{Diagnosis}

Frontal organ formed by 2 reticulated and expanded branches; 5 blades finely reticulated in the lateral organs; 5 setae on deutotritosternum; 7 pairs of short setae on propeltidium; 3 pairs of setae with similar length on metapeltidium; cheliceral fingers with 9 teeth each; coxae II-IV with 3, 3, 1 thick setae, respectively; 5 setae ( $g r t, r$, esp and 2 esd) on basitarsus of leg IV; opisthosomal tergites II-VI with two pairs of setae $t$ between one setae $s$ on each side; opisthosomal sternites IV-VI with three pairs of $a$ setae ( $a_{1}$ shorter than $a_{2}$ and $a_{3}$ ) flanked by one $s$ seta on each side; opisthosomal segment XI with 2 pairs of ventral setae arranged in 2 rows; first lobe of female genitalia with 10 pairs of setae; flagellum formed by 14 moniliform segments with setae of different lengths, including very long setae inserted in a $\mathrm{V}$ arrangement from the sixth flagellar segment onwards. 


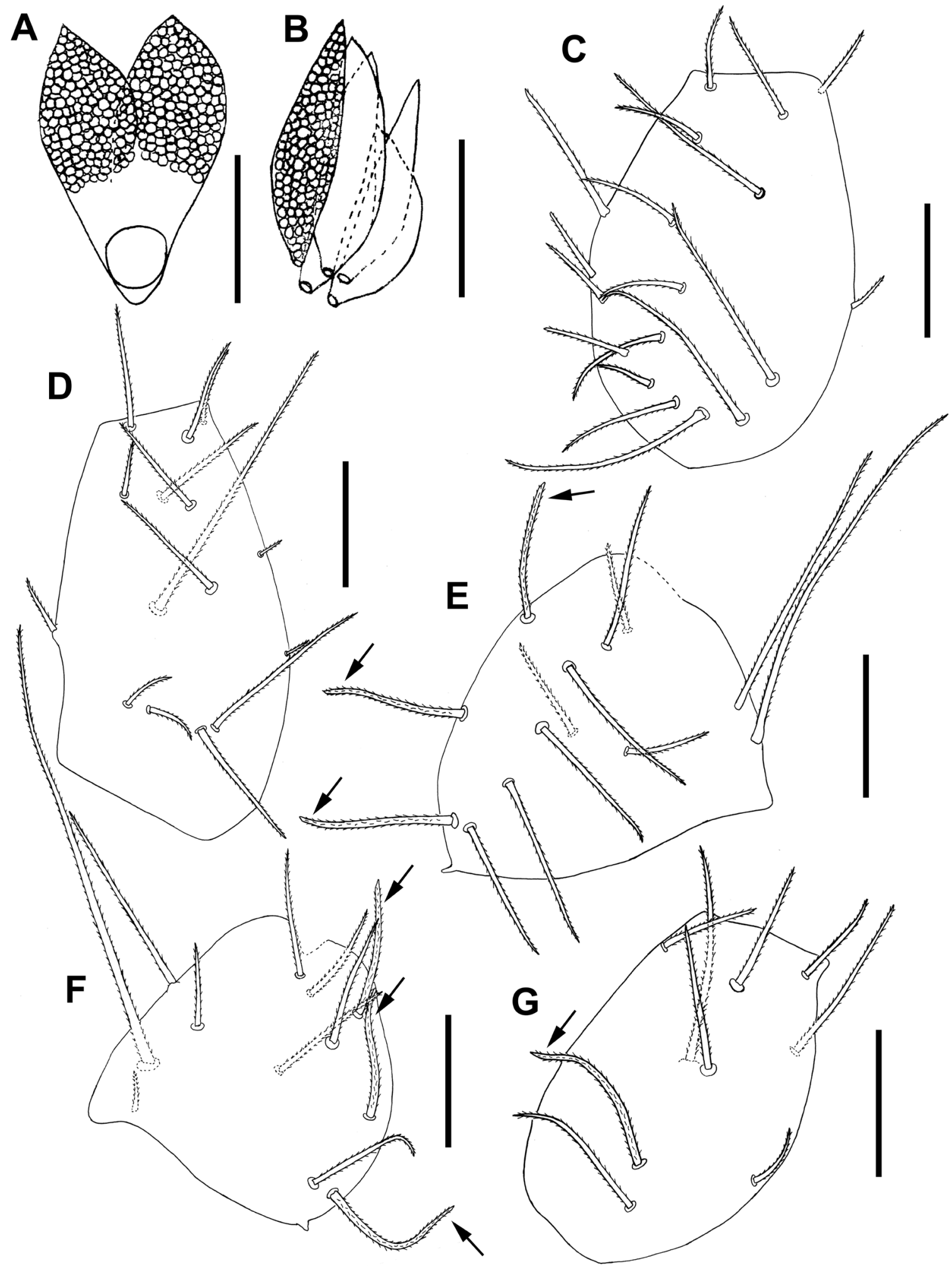

Fig. 3. Allokoenenia canhembora sp. nov.,, , holotype (ISLA 50394). A. Frontal organ. B. Blades of lateral organ. C. Coxa of left pedipalp. D. Coxa of left leg I. E. Coxa of right leg II. F. Coxa of left leg III. G. Coxa of right leg IV. Scale bars: A-B $=20 \mu \mathrm{m}$. $\mathrm{C}-\mathrm{G}=40 \mu \mathrm{m}$. Thickened setae on coxae II-IV indicated by arrows. 


\section{Etymology}

The species ephitet is derived from a word of the Tupi language meaning 'fugitive'. The species received this name due to the difficulty of capturing the specimens, which quickly ran away and hid under the calcite plates on the cave floor as soon as they were discovered (see: Habitats and threats). The name is to be treated as a noun in apposition.

\section{Material examined}

\section{Holotype}

BRAZIL • O; Bahia, Campo Formoso, Toca do Gonçalo Cave; 10³0'40.94" S, 4053'42.10" W; $527 \mathrm{~m}$ a.s.1.; 11 Jun. 2012; R.L. Ferreira leg.; ISLA 50394.

\section{Other material}

BRAZIL・ 1 \%; same collection data as for holotype; 16 Mar. 2014; ISLA 50395.
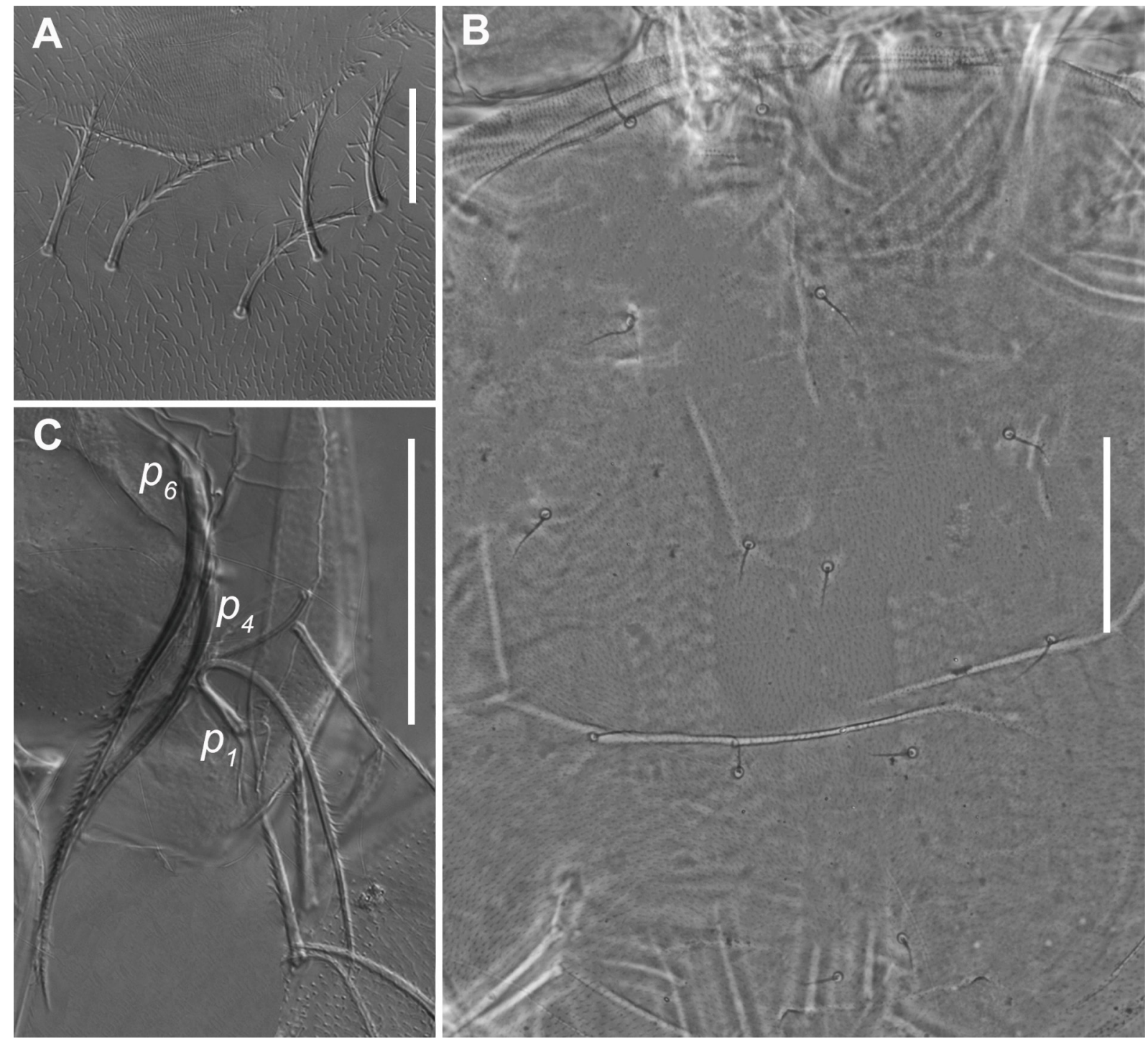

Fig. 4. Allokoenenia canhembora sp. nov., + , holotype (ISLA 50394). A. Deutotritosternal setae. B. Propeltidial chaetotaxy. C. Proximal setae $\left(p_{1}-p_{6}\right)$ on basal segment of chelicera ( $p_{5}$ out of focus). Abbreviations: see Material and methods. Scale bars: $A=20 \mu \mathrm{m} ; \mathrm{B}=50 \mu \mathrm{m} ; \mathrm{C}=45 \mu \mathrm{m}$. 


\section{Description}

\section{Adult female}

MeAsurements And RAtios. See Table 2.

Body LENGTH. Without flagellum: $1420 \mu \mathrm{m}$.

Prosoma. Frontal organ formed by two reticulated and expanded branches (42 long), with blunt tips (Fig. 3A). Lateral organ with 5 blades pointed-lanceolate (32 long) and finely reticulated (Fig. 3B). Propeltidium with $7+7$ short setae (Fig. 4B). Setae $t_{1}, t_{2}$ and $t_{3}$ of metapeltidium 77, 75 and 77 long, respectively. Deuto-tritosternum with 5 setae in U-shaped arrangement (Fig. 4A). Labrum with $5+5$ short setae. Basal segment of chelicera 195 long (dorsal length), with 6 proximal setae ( $p_{4}$ and $p_{6}$ thickened and densely barbed; $p_{1}$ slightly thinner and barbed) (Fig. 4C), and 3 distal setae: $d_{3}$ (107) longer than $d_{1}$ (60) and $d_{2}(62) ; d_{3}$ smooth near base and barbed in its distal half, $d_{1}$ and $d_{2}$ thin, flexible and with tiny

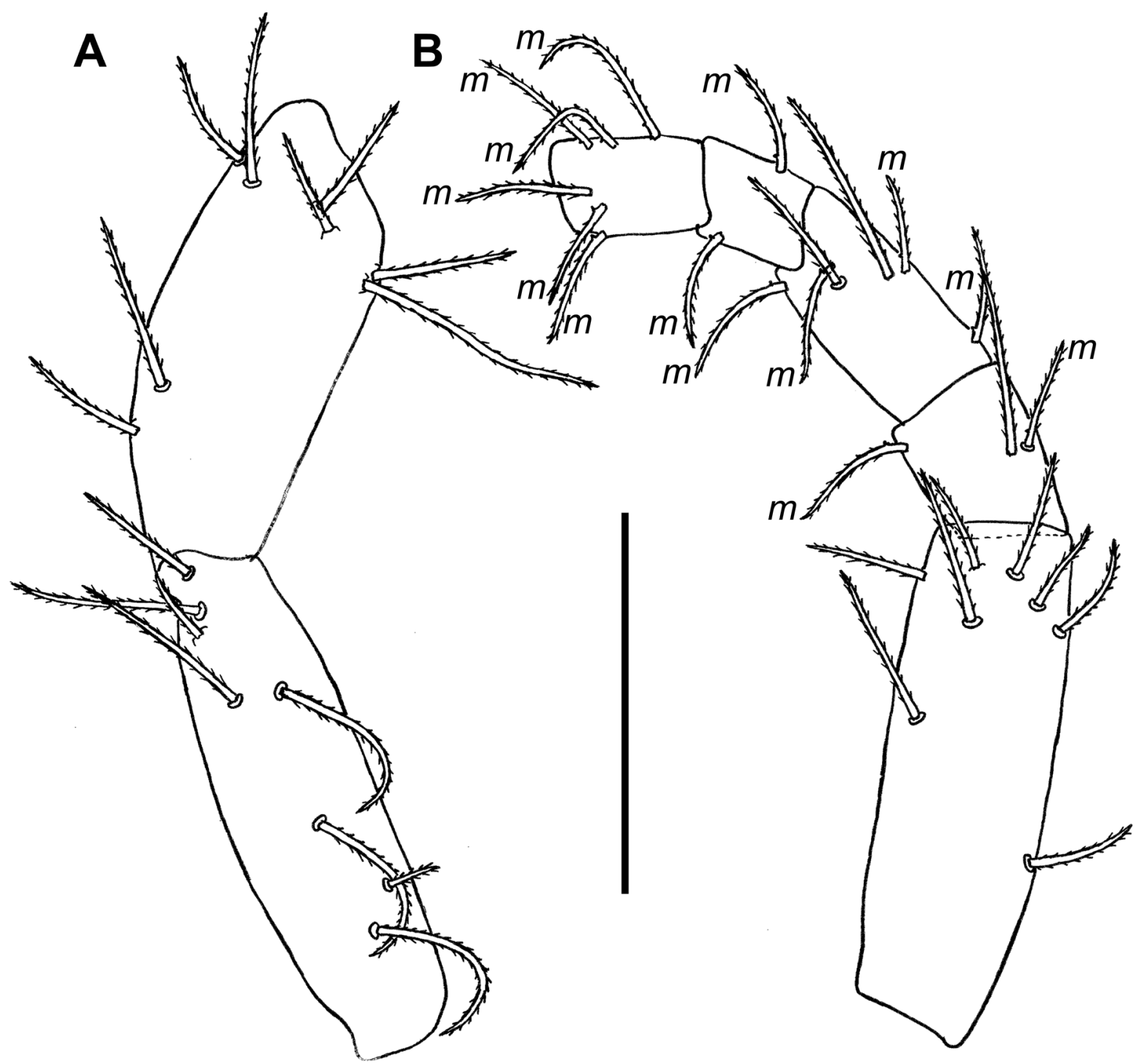

Fig. 5. Allokoenenia canhembora sp. nov.,, , holotype (ISLA 50394). A. Trochanter-femur of right pedipalp. B. Tibia-tarsus 2 of left pedipalp. Abbreviations: see Material and methods. Scale bar $=100 \mu \mathrm{m}$. 


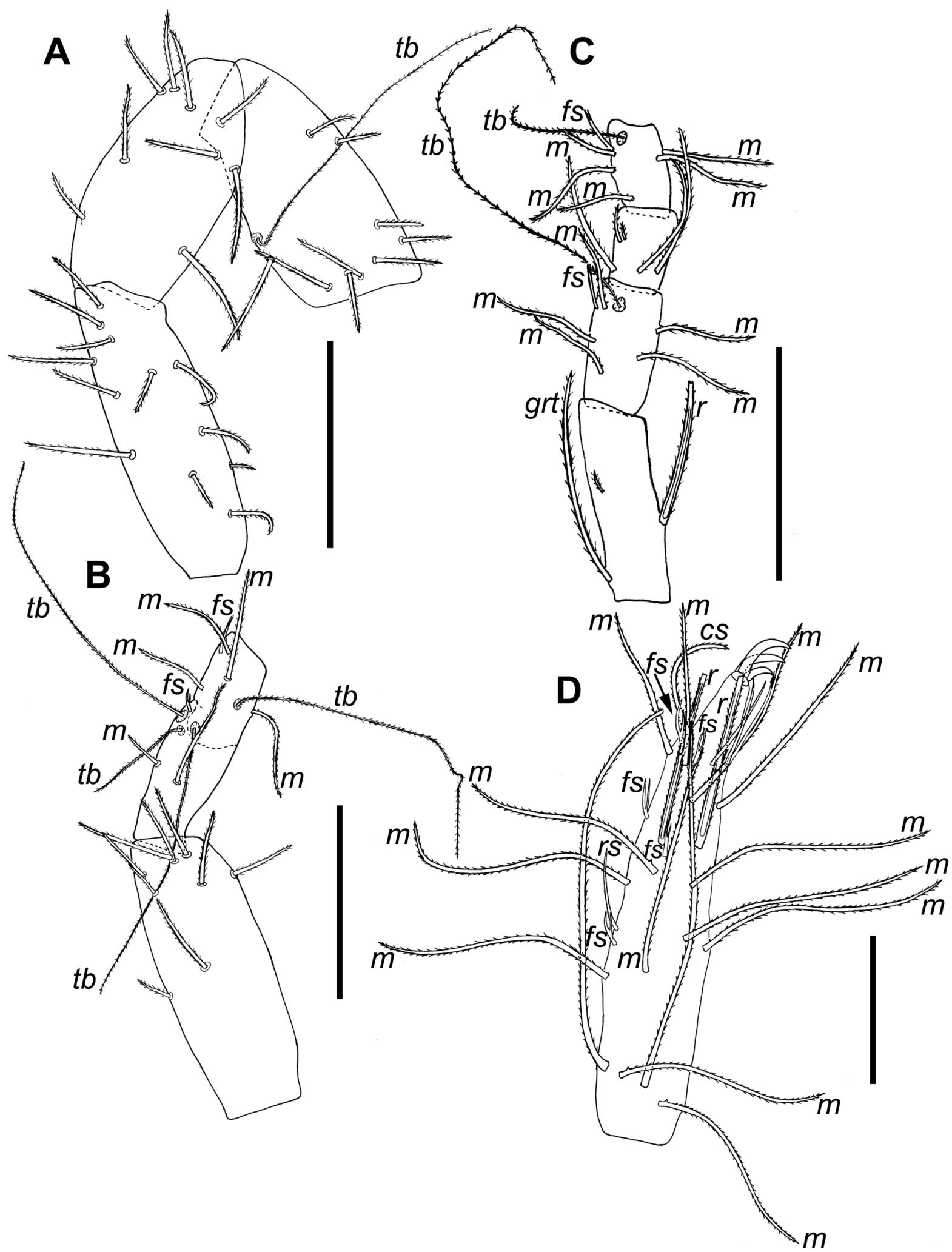

Fig. 6. Allokoenenia canhembora sp. nov., + , holotype (ISLA 50394). A. Trochanter-patella of right leg I. B. Tibia-basitarsus 2 of left leg I. C. Basitarsus 3-tarsus 2 of left leg I. D. Tarsus 3 of right leg I. Abbreviations: see Material and methods. Scale bars: A-C $=100 \mu \mathrm{m} ; \mathrm{D}=40 \mu \mathrm{m}$. 
projections in apex; and one apical seta. Hand of chelicera with 7 setae: 4 dorsal setae, 2 setae in its outer portion ( 1 close to articulation of movable finger and 1 on a tubercle close to teeth of fixed finger) and 1 seta inserted in its inner portion. Fingers with 9 teeth each.

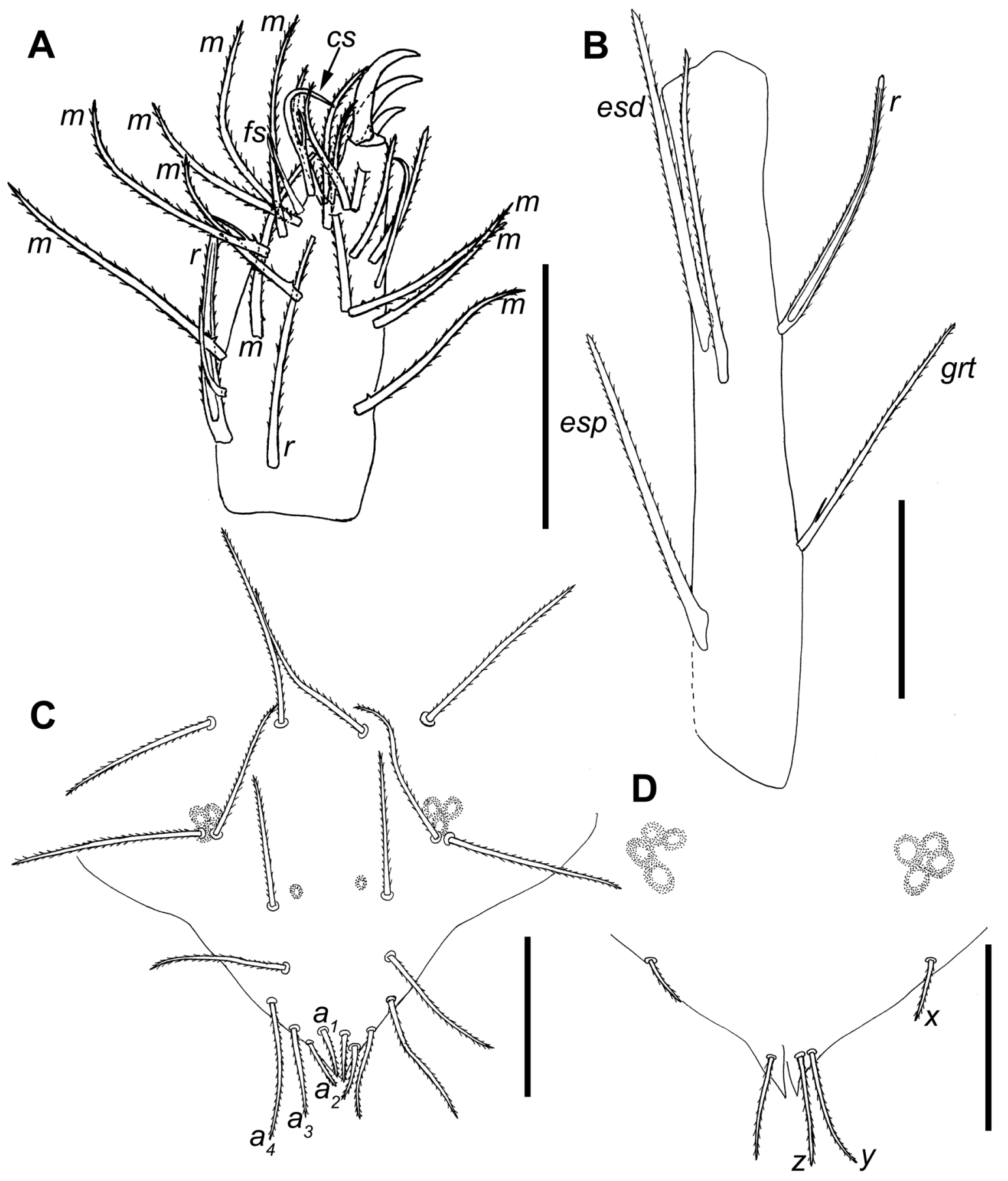

Fig. 7. Allokoenenia canhembora sp. nov., o, holotype (ISLA 50394). A. Tarsus 3 of left pedipalp. B. Basitarsus of right leg IV. C. First lobe of female genitalia. D. Second lobe of female genitalia. Scale bars $=40 \mu \mathrm{m}$. Dotted circles and ellipses in figures $\mathrm{C}$ and D represent cuticular orifices. Abbreviations: see Material and methods. 
Coxal chaetotaxy. Pedipalp coxa with 18 setae (Fig. 3C); coxa I with 13 ordinary setae and two microsetae (Fig. 3D); coxa II with 3 thick setae, 2 macrosetae and 8 ordinary setae (Fig. 3E); coxa III with 3 thick setae, 1 macroseta, and 8 ordinary setae (including 1 small seta adjacent to macroseta) (Fig. 3F) and coxa IV with 1 thick and 8 ordinary setae (Fig. 3G).

PedipalP. $t c$ with 8 setae ( 2 considerably smaller than others); $f e$ with 8 setae (Fig. $5 \mathrm{~A}$ ); $t i$ with 8 setae; btal with $2 m$ and 1 normal seta; bta 2 with 2 normal setae and $4 m$; tal with $2 m$; ta 2 with $6 m$ (Fig. 5B); ta 3 with 1 long $f s, 1 c s$ with a conspicuous spine, $2 r, 10 \mathrm{~m}$ (one macroseta with basal denticle and conspicuous spine) and 10 normal setae (Fig. 7A).

LEG I. $t c$ with 12 normal setae ( 1 considerably smaller than others); $f e$ with 9 normal setae; $p a$ with 9 normal setae and $1 \mathrm{tb}$ (Fig. 6A); $t i$ with 9 normal setae; btal with $1 \mathrm{~m}, 1$ normal seta, $2 \mathrm{tb}$ and $1 \mathrm{fs}$ (with inner branch shorter than outer branch); bta 2 with $4 m, 2 t b$ and 1 long $f_{s}$ (Fig. 6B); bta3 with $1 r$, $1 \mathrm{grt}$ and 1 short normal seta; bta 4 with $5 \mathrm{~m}, 1 \mathrm{tb}$ and 1 long $f s$; $t a 1$ with 5 normal setae ( 2 considerably smaller than others); $t a 2$ with $5 \mathrm{~m}, 1 \mathrm{tb}$ and 1 long $f_{s}$ (Fig. 6C); ta3 with $5 f_{s}$ (with subequal branches) arranged as $f_{s_{1}} / f s_{2} / f s_{3} / f s_{4+5}, r s\left(r s / f s_{1}=2.2\right), 2 r, 1 \mathrm{cs}, 13 \mathrm{~m}$ and 5 normal setae (Fig. 6D).

LEG II. $t c$ with 3 normal setae; $f e$ with $1 m$ and 4 normal setae; $p a$ with $2 m, 1$ thick seta, and 2 normal setae; $t i$ with 1 thick seta and 4 normal setae; bta with 6 normal setae; $t a$ with $1 \mathrm{r}, 1 \mathrm{~m}$ and 9 normal setae.
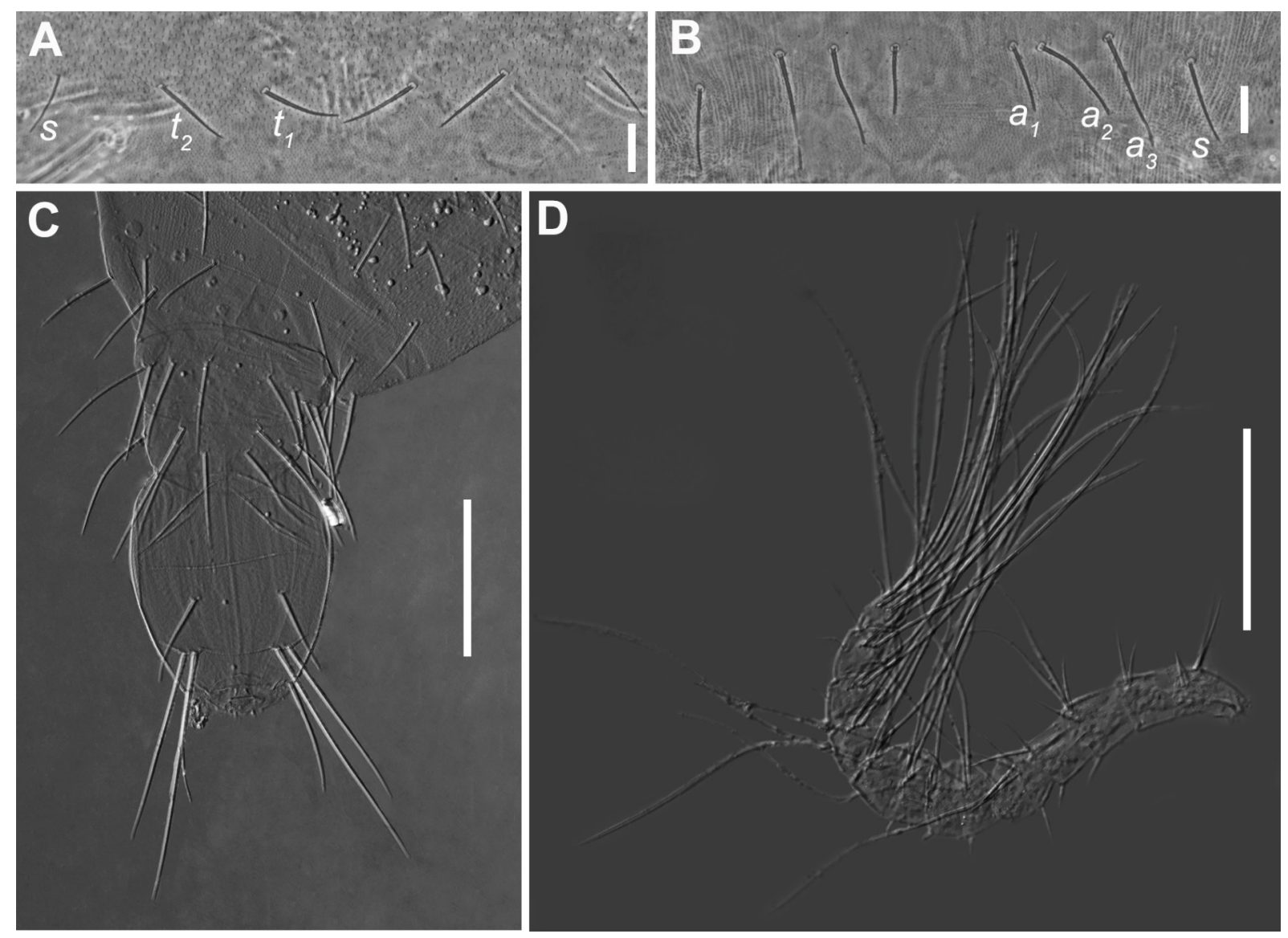

Fig. 8. Allokoenenia canhembora sp. nov., + , holotype (ISLA 50394). A. Chaetotaxy of opisthosomal tergite III. B. Chaetotaxy of opisthosomal sternite VI. C. Opisthosomal segments VIII-XI. D. Flagellum. Abbreviations: see Material and methods. Scale bars: A-B $=20 \mu \mathrm{m} ; \mathrm{C}-\mathrm{D}=100 \mu \mathrm{m}$. 
LEG III. $t c$ with 2 normal setae; $f e, p a$, and $t i$ with 1 thick seta and 4 normal setae each; $b t a$ with 6 normal setae; $t a$ with $1 r, 1 m$ and 9 normal setae.

LeG IV. $t c$ with 3 normal setae; $f e$ with $1 m$ and 2 normal setae; $p a$ and $t i$ with 1 thick and 4 normal setae each; bta with grt, $r$, esp, and 2 esd; tal with 4 normal setae; ta2 with 8 normal setae.

IV втA. $7.2 \times$ longer than wide and with 5 setae ( $g r t, r$, esp and 2 esd $)$. Seta $r$ inserted in distal half $(d r /$ $I V b t a=0.64)$ and grt inserted in proximal half of segment (Fig. 7B).

Opisthosoma. Tergites II-VI with $3+3$ dorsal setae, two pairs of $t$ setae $\left(t_{1}=35-41 \mu \mathrm{m}, t_{2}=37-42 \mu \mathrm{m}\right)$ between a pair of slender setae $(s=27-35 \mu \mathrm{m})$ (Fig. 8A). Sternite III with $2+2$ setae. Sternites IV-VI each with $3+3$ thickened setae $\left(a_{1}=30 \mu \mathrm{m}, a_{2}=41-45 \mu \mathrm{m}, a_{3}=48-53 \mu \mathrm{m}\right)$ between a pair of slender setae $(s=36-40 \mu \mathrm{m})$ (inserted caudal to thick setae); pair of pores present between $a_{1}$ setae on sternites IV-VI (Fig. 8B). Presence of inconspicuous paired cavities in intersegmental furrows between sternites III-IV, IV-V, V-VI and VI-VII, one at each side of opisthosoma. Segments VII-X with 8 setae each (4 dorsal and 4 ventral). Segment XI elongated $(1.15 \times$ as long as wide), with dorsal row of $2+2$ long setae (inner pair $=160 \mu \mathrm{m}$; outer pair $=117-125 \mu \mathrm{m}$ ) inserted in its distal half and 2 pairs of ventral setae, 1 inserted around middle of segment $(60 \mu \mathrm{m})$ and other inserted in apical region $(75 \mu \mathrm{m})$ (Fig. 8C). Intermediate ring of flagellum reduced in size $(11 \mu \mathrm{m})$ and bears 2 tiny setae $(8 \mu \mathrm{m})$.

Female Genitalia. First lobe with $10+10$ setae in 5 transverse rows: $2+2$ sternal setae $\left(s t_{1}, s t_{2}\right)$ followed by $2+2,1+1,1+1$ and $4+4$ distal setae $\left(a_{1}=11 \mu \mathrm{m} ; a_{2}=12 \mu \mathrm{m} ; a_{3}=20 \mu \mathrm{m} ; a_{4}=30 \mu \mathrm{m}\right)$; interior surface of the first lobe with a group of 3 orifices on either side and a medial pair of small orifices (Fig. 7C). Second lobe with $3+2$ setae, asymmetry caused by lack of $1 y$ seta $(x=15 \mu \mathrm{m} ; y=29 \mu \mathrm{m} ; z=27 \mu \mathrm{m})$, and with cuticular spines; presence of group of 4 orifices on each half (Fig. 7D).

Flagellum. Arched and formed by 14 short and moniliform segments. First flagellar segment with 4 short setae $(21-44 \mu \mathrm{m})$; second with 2 short setae $(27-30 \mu \mathrm{m})$; third with 2 long setae $(75 \mu \mathrm{m})$ and 4 short setae $(10-30 \mu \mathrm{m})$; fourth with 3 short setae $(15-31 \mu \mathrm{m})$; fifth with 5 short setae $(25-33 \mu \mathrm{m})$; sixth with 2 very long setae; seventh with 1 short seta $(15 \mu \mathrm{m})$ and 4 very long setae; eighth with 3 short setae $(10-15 \mu \mathrm{m})$ and 2 very long setae; remaining segments bear 1 short seta $(10-23 \mu \mathrm{m})$ and 4 very long setae each (Fig. 8D). Very long setae inserted laterally on segments, being arranged in $\mathrm{V}$ along flagellum (Fig. 9H). Length $(\mu \mathrm{m})$ and total number of setae $(\mathrm{N})$ of flagellar articles available in Table 1.

\section{Male and immatures}

Unkown.

\section{Distribution}

Known only from the type locality.

\section{Remarks}

Allokoenenia canhembora sp. nov. belongs to the genus Allokoenenia mainly because of the shape of the last opisthosomal segments and flagellum (Figs 8C-D, 9F-H). It shares with $A$. afra the presence of a short and arched flagellum formed by 14 moniliform segments, the chaetotaxy of opisthosomal sternites IV-VI $(1 s+3 a+3 a+1 s)$, and the arrangement of the ventral setae of the last opisthosomal segment (in two rows) (Figs 2, 8C). However, they can be distinguished by the shape of the frontal organ (Figs 1C, 3A), and by the number of blades on lateral organs (5 vs 1 ) and deutotritosternal setae (5 vs 1) (Silvestri, 1913). Furthermore, we observed that the immature specimen of $A$. afra has 6 setae on basitarsus IV ( $g r t, r, g l a$, esp and 2 esd). This feature was not visible in the adults and was not described by Silvestri (1913), but they probably have at least 6 setae, since in general the setation of this article is 

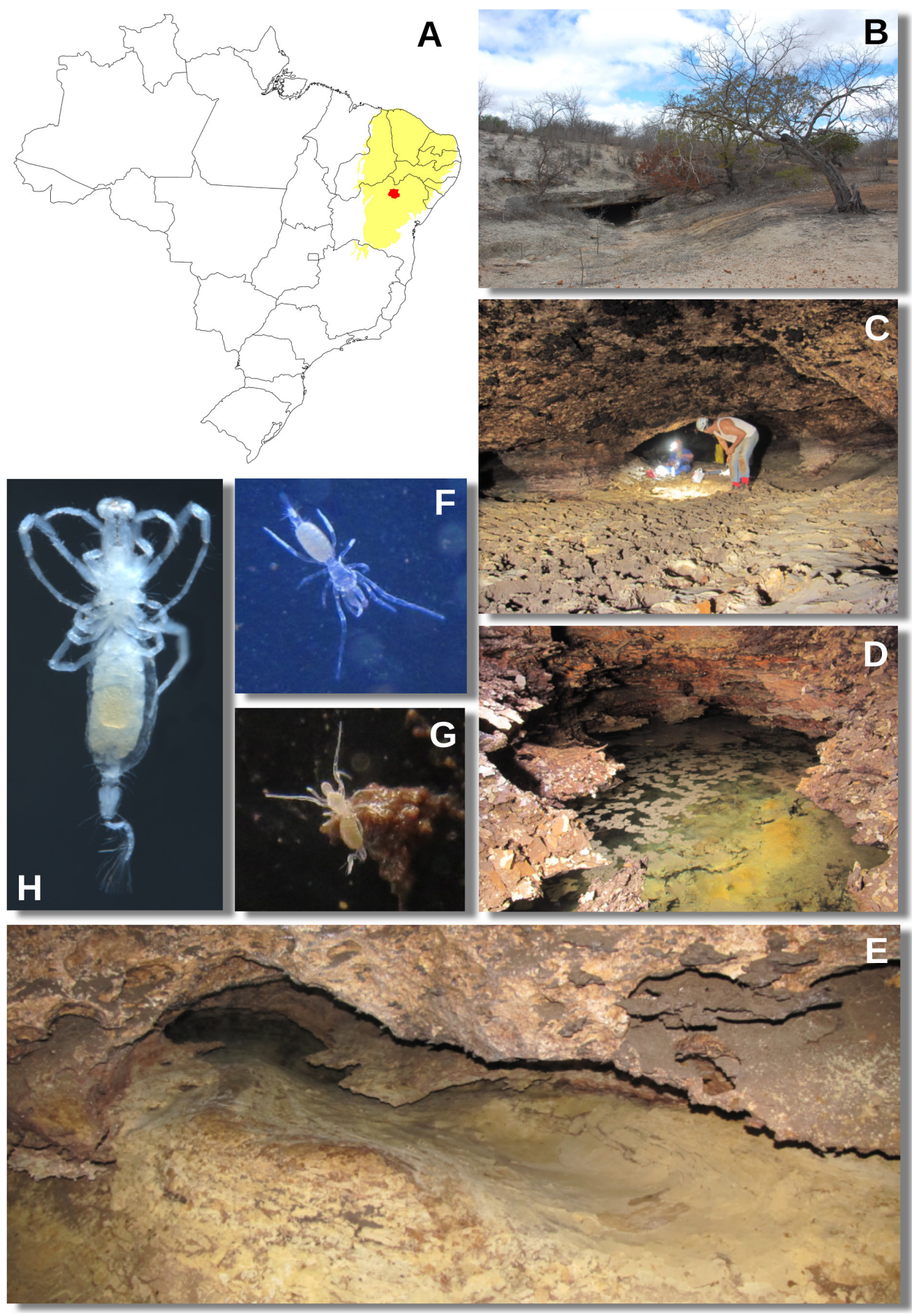

Fig. 9. Allokoenenia canhembora sp. nov. A. Map of Brazil showing the placement of the Caatinga Biome, delimited in yellow, and of Toca do Gonçalo Cave (red dot), the type locality of $A$. canhembora sp. nov. B. Entrance of Toca do Gonçalo Cave and its surrounding landscape, characterized by the semiarid climate. C. Gallery of the lower level (right branch) of Toca do Gonçalo Cave, where individuals of A. canhembora sp. nov. were observed. D. Puddle of water inside the Gruta do Gonçalo Cave, with numerous calcite rafts on its surface. E. Area of the cave devoid of water with muddy substrate covered by many layers of calcite rafts. F-G. Live specimens photographed on a tray before being captured. H. Habitus of the specimen (ISLA 50395) captured in 2014 under a stereo microcope. 
already complete in immatures of this stage or they have fewer setae than the adults. In the new species, the basitarsus IV bears only 5 setae ( $g r t, r$, esp and 2 esd). Some flagellar characters can also be useful to distinguish these two species: the flagellar segments 1-3, 5, 7 and 9 of $A$. afra bear the typical apical cuticular spines present in the flagellum of other palpigrades, as well as setae of uniform shape despite showing some variation in their lengths, as represented in Silvestri (1913: 216, fig. VI, 5) and confirmed by the study of the specimens (Fig. 1B); in A. canhembora sp. nov., the cuticular spines are absent and the flagellar segments carry setae of very different lengths and shapes, including very short (around $10-15 \mu \mathrm{m}$ ) to very long setae (longer than $100 \mu \mathrm{m}$ ).

\section{Habitat and threats}

The Toca do Gonçalo Cave is associated to carbonatic rocks from the Caatinga geological group, which comprises relatively young rocks deposited around three million years ago under a lacustrine condition. Such rocks are closely inserted to old carbonatic rocks from the Una geological group, from the Neoproterozoic. The cave is located in a semiarid biome (the Caatinga Formation), in the Campo Formoso Municipality, Bahia State, Northeastern Brazil (Fig. 9A). It presents around $500 \mathrm{~m}$ of topographed conduits and a single horizontal lenticular-shaped entrance (Fig. 9B), which connects to a descending conduit. This cave presents two distinct levels: the upper level (which corresponds to the left branch of the cave), is predominantly dry, and the lower level (corresponding to the right branch) is quite humid (Fig. 9C) (Souza-Silva \& Ferreira 2016). The lower level used to be mostly submerged by the water table, but it is currently accessible, since the water table reduced dramatically, as will be discussed further on. The main sources of organic matter for both terrestrial and aquatic species is the dissolved and particulate organic matter imported from the external habitats during strong rains, but also the small guano deposits and some root mats that can be used as food by invertebrates. The Toca do Gonçalo Cave is considered a hotspot of subterranean biodiversity (only three hotspots are currently known to South America), presenting 22 troglobitic species (Souza-Silva \& Ferreira 2016). Hostpots of subterranean biodiversity are those caves (or cave systems) with 20 or more cave-restricted species (Culver \& Sket 2000). However, most troglobitic species from this cave remain undescribed.

All individuals of $A$. canhembora sp. nov. were found at the lower cave level, always in very damp areas. In 2012, several specimens were observed, but only a single exemplar was captured since the cave substrata in the area prevented us to collect most of them. The water in karst systems usually presents high contents of dissolved calcium carbonates, which sometimes can form conspicuous deposits in the water surface inside caves. Such formations are usually called "calcite rafts" and are considered to be a kind of speleothem (Fig. 9D). Since the water table in Toca do Gonçalo Cave used to fluctuate in time, the areas devoid of water usually present a muddy substrate covered by many layers of calcite rafts (Fig. 9E). Most specimens of $A$. canhembora sp. nov. were found below those calcite rafts, so in most cases, as soon as we turned a piece of calcite, the specimen used to run away and hide in the uncountable small spaces between the layers, thus making their capture unfeasible. This is the reason why we decided to name the species "canhembora", meaning 'fugitive' as explained in the etymology. A visit in 2013 revealed specimens (although in smaler number in comparison to 2012), but none could be captured. Finally, in 2014, we could find a single specimen that was successfully sampled (Fig. 9F-H).

All the cave visits from 2015 onward resulted in no further observations of specimens. Since the lower level of the cave was extremely dry, we believe that the specimens had probably migrated to inaccessible lower compartments. However, it is important to emphasize the fact that this species might be seriously threatened, as are other cave-restricted species from the Toca do Gonçalo Cave. This cave has been the target of several human impacts, which were highly intensified over the last years. In 1997, one of the authors (RLF) could attest that most part of the lower level was inaccessible due to the high level of the water table. In that period, the villagers of Gonçalo settlement used to draw water from the cave for their subsistence and this practice occurred during decades, by means of a diesel pump installed 
inside the cave. The villagers used to remove water from the cave once a week, thus the water table was persisting (although varying along the time), since the amount of water pumped out from the cave was negligible. However, an electric pump used by a local farmer for irrigation was installed in the cave in 2010 (Prevorčnik et al. 2012; Souza-Silva \& Ferreira 2016). According to the villagers, this pump remained active during the whole day. In one of our surveys in 2010, a pronounced decrease of the water table (at least two meters) was observed. In 2012, the equipments were removed from the cave since the National Cave Research and Conservation Center intervened and asked the municipal government to dig an artesian well for the villagers. In December 2018, a cave visit revealed that the water table was no longer observed. Hence, previously inaccessible areas could be explored, revealing the cave to be much longer than thought. However, from the 22 troglobitic species occurring in this cave, only two (an isopod and a springtail) were observed in this visit, in some moist areas located deep inside the cave. No specimens of $A$. canhembora sp. nov. were observed, despite the intense efforts employed by the team in searching for them. The villagers mentioned that the building of a reservoir some dozens of kilometers from the cave, has altered the water balance, so that eventual flooding that used to reach the area never occurred again. Therefore, the Toca do Gonçalo Cave is seriously threatened and it is crucial that the Brazilian government intervene, in order to ensure the protection of this unique habitat in South America.

\section{Allokoenenia stygia sp. nov. urn:Isid:zoobank.org:act:C37DF62D-1144-4E02-9076-4BF344AEB140}

Figs 10-19

\section{Diagnosis}

Frontal organ formed by 2 reticulated and lanceolate branches; 3 blades finely reticulated in the lateral organs; 5 setae on deutotritosternum; 7 pairs of short setae on propeltidium; 3 pairs of setae with similar lengths on metapeltidium; cheliceral fingers with 9 teeth each; 2 thickened dorsal setae proximally inserted in the cheliceral hand; coxae II-IV with 3, 3, 0 thick setae, respectively; 6 setae ( $g r t, r$, gla, esp and 2 esd) on basitarsus of leg IV; opisthosomal tergites II-VI with 2 pairs of robust setae (one pair of setae $t$ between one setae $s$ on each side); opisthosomal sternites IV-VI with 2 pairs of $a$ setae flanked by $1 s$ seta on each side; opisthosomal segment XI with 2 pairs of ventral setae arranged in 2 rows; first lobe of female genitalia with 11 pairs of setae.

\section{Etymology}

The species epithet is derived from Styx, a Titan goddess and also one of the five rivers that form the boundary between Earth and the Underworld according to Greek mythology. From the Latin 'stygius' derived from the Ancient Greek ' $\Sigma \tau v \gamma$ los' ('Stúgios', 'relating to Styx'), from ' $\Sigma \tau v \gamma \xi$ ' ('Stúx', 'Styx, chief river of underworld'). The name is a noun in apposition.

\section{Material examined}

\section{Holotype}

BRAZIL • +; Pará, Canaã dos Carajás, SB_0114 cave; 6²1'10.22" S, 4958'38.20" W; 326 m a.s.1.; 10-31 Jan. 2013; F.F. Pellegatti et al. leg.; MZSP 54247.

\section{Paratype}

BRAZIL • 1 +; Pará, Canaã dos Carajás, SB_0112 cave; 6²1'12.66" S, 4958'38.20" W; 331 m a.s.1.; 10-31 Jan. 2013; F.F. Pellegatti et al. leg.; MZ̄SP 54249. 


\section{Description}

\section{Adult female}

Measurements and Ratios. See Table 2.

Body LeNGTH. Without flagellum: 1030-1295 $\mu \mathrm{m}$.

Prosoma. Frontal organ formed by 2 reticulated and lanceolate branches (40 long) (Fig. 10A). Lateral organ with 3 blades pointed-lanceolate (24-27 long) and finely reticulated (Fig. 10B). Propeltidium with $7+7$ short setae (Fig. 10D). Setae $t_{1}, t_{2}$ and $t_{3}$ of metapeltidium 72-75, 67-80 and 80-82 long, respectively (Fig. 10C). Deuto-tritosternum with 5 setae in U-shaped arrangement (Fig. 11A). Labrum with $5+5$ short setae. Basal segment of chelicera 280-310 long (dorsal length), with 6 proximal setae ( $p_{4}$ and $p_{6}$ thickened and densely barbed; remaining setae sparsely barbed, with $p_{5}$ more conspicuous than usual) (Fig. 11B), and 3 distal setae: $d_{3}$ (142) longer than $d_{1}$ (55-60) and $d_{2}(62)$; $d_{3}$ smooth near base and barbed in distal half, $d_{1}$ and $d_{2}$ thin, flexible and with tiny projections at apex (Fig. 10E); and 1 apical seta. Hand of chelicera with 7 setae: 4 dorsal setae ( 2 inserted close to base of article and considerably thicker than others) (Fig. 11D), 2 setae in outer portion (1 close to articulation of movable finger and 1 on tubercle close to teeth of fixed finger) and 1 seta inserted in inner portion. Fingers with 9 teeth each.

Coxal chaetotaxy. Pedipalp coxa with 18 setae (Fig. 12A); coxa I with 11 ordinary setae and 2 microsetae (Fig. 12B); coxa II with 3 thick setae, 2 macrosetae, and 8 ordinary setae (Fig. 12C); coxa III with 3 thick setae, 1 macroseta, and 8 ordinary setae (including 1 small seta adjacent to macroseta) (Fig. 12D) and coxa IV with 8 ordinary setae (thick seta absent) (Fig. 12E).

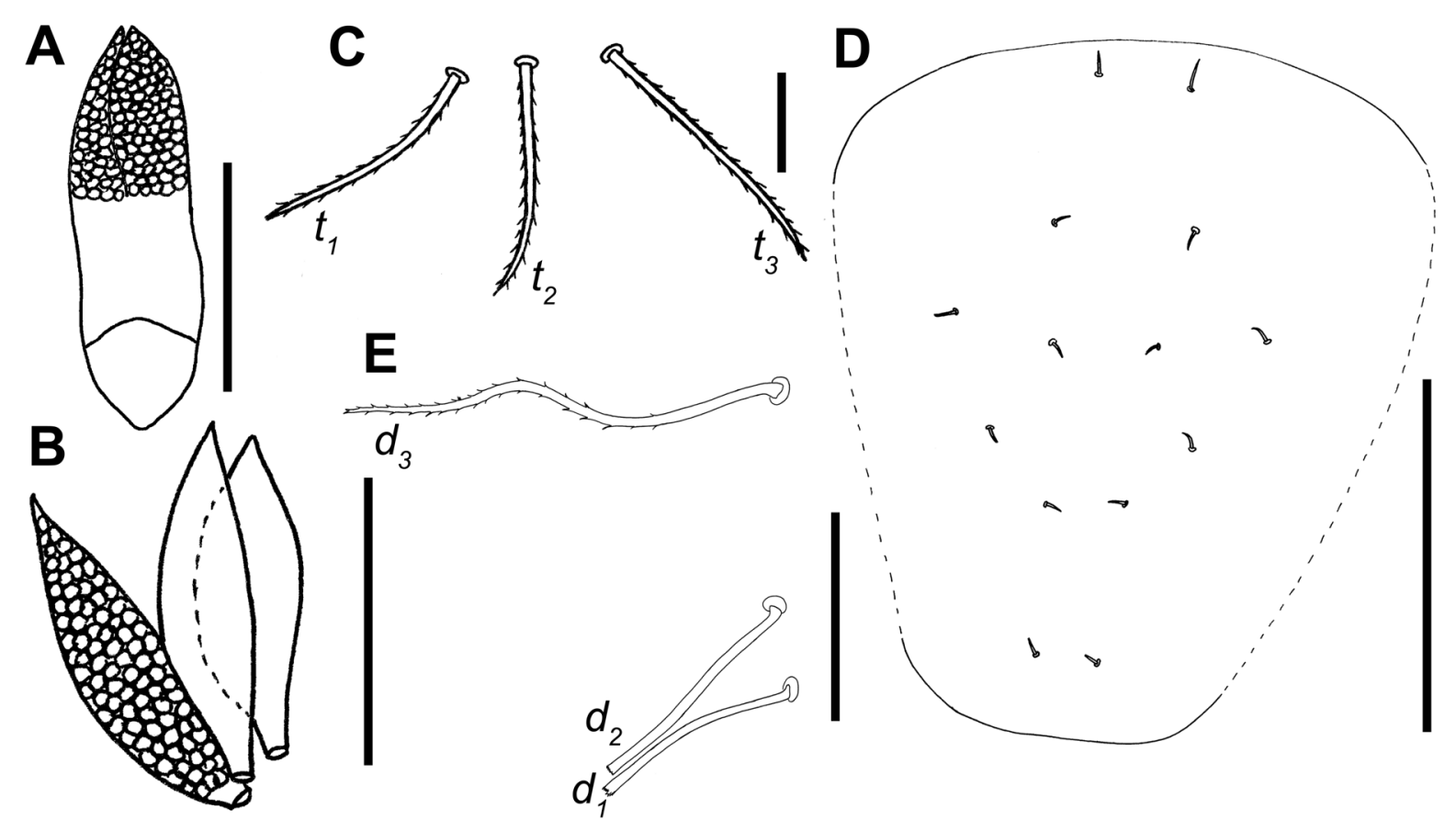

Fig. 10. Allokoenenia stygia sp. nov., ․ . A. Frontal organ, holotype (MZSP 54247). B. Blades of lateral organ, paratype (MZSP 54249). C. Metapeltidial chaetotaxy, holotype (MZSP 54247). D. Propeltidial chaetotaxy, holotype (MZSP 54247). E. Distal setae $\left(d_{1}-d_{3}\right)$ on basal segment of chelicera, paratype (MZSP 54249). Abbreviations: see Material and methods. Scale bars: $A-B=20 \mu \mathrm{m}$; $C=25 \mu \mathrm{m}$; $\mathrm{D}=150 \mu \mathrm{m} ; \mathrm{E}=60 \mu \mathrm{m}$. 
Pedipalp. $t c$ with 8 ( 9 in paratype) setae ( 2 considerably smaller than others); $f e$ with 8 setae; $t i$ with 8 setae; btal with $2 \mathrm{~m}$ and 1 normal seta; bta 2 with 2 normal setae and $4 \mathrm{~m}$; tal with $2 \mathrm{~m}$; ta2 with $6 \mathrm{~m}$ (Fig. 13); ta 3 with 1 long $f s, 1 c s$ with conspicuous spine, $2 r, 8 m$ (1 with basal denticle and conspicuous spine) and 12 normal setae (Fig. 16A).
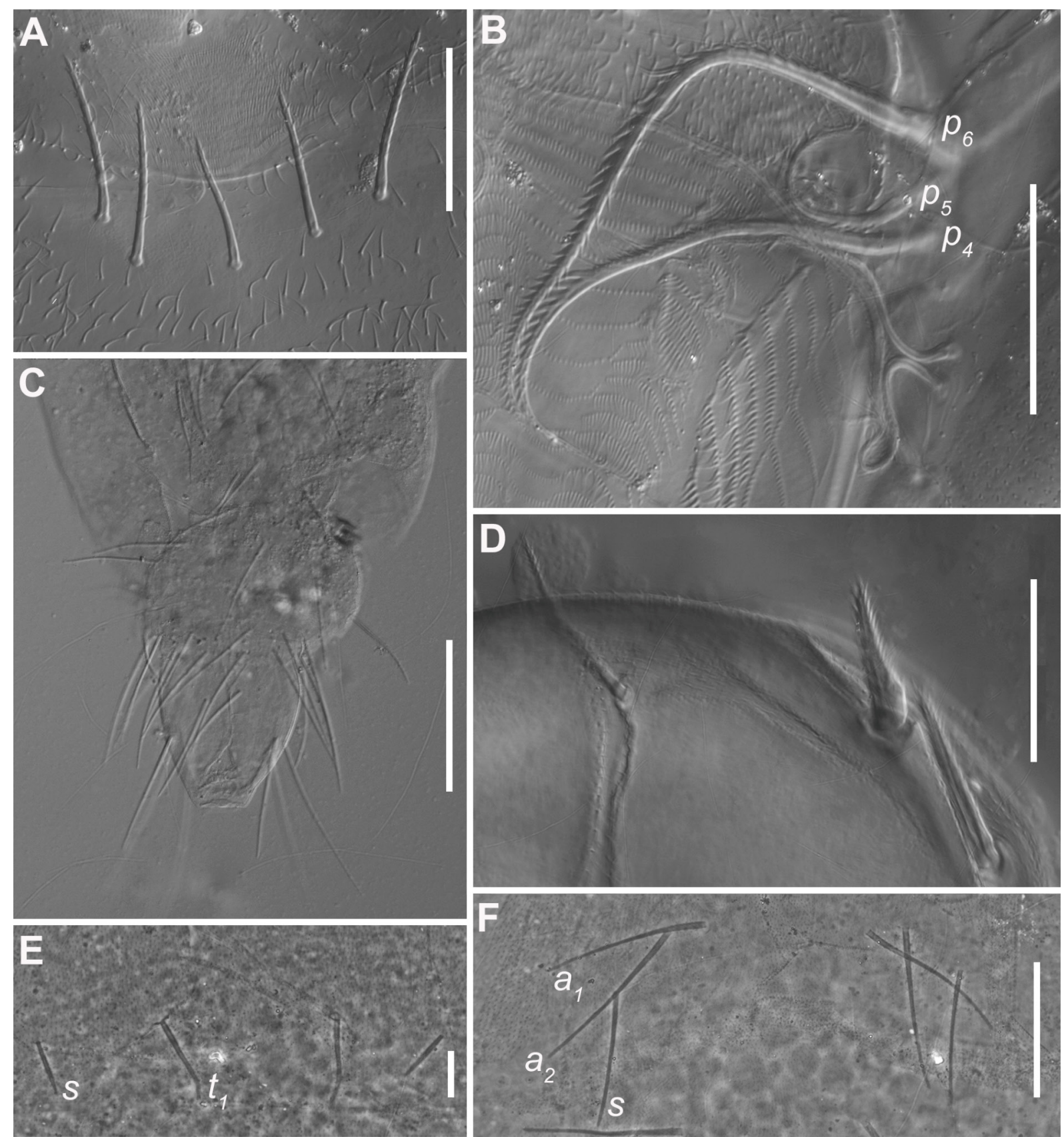

Fig. 11. Allokoenenia stygia sp. nov.,, . A. Deutotritosternal setae, holotype (MZSP 54247). B. Proximal setae $\left(p_{1}-p_{6}\right)$ on basal segment of chelicera ( $p_{1}$ out of focus), holotype (MZSP 54247). C. Opisthosomal segments VII-XI, paratype (MZSP 54249). D. Proximal region of cheliceral hand showing the two thickened setae, holotype (MZSP 54247). E. Chaetotaxy of opisthosomal tergite IV, paratype (MZSP 54249). F. Chaetotaxy of opisthosomal sternite IV, paratype (MZSP 54249). Abbreviations: see Material and methods. Scale bars: A-B $=30 \mu \mathrm{m} ; \mathrm{C}=100 \mu \mathrm{m} ; \mathrm{D}=35 \mu \mathrm{m} ; \mathrm{E}-\mathrm{F}=20 \mu \mathrm{m}$. 


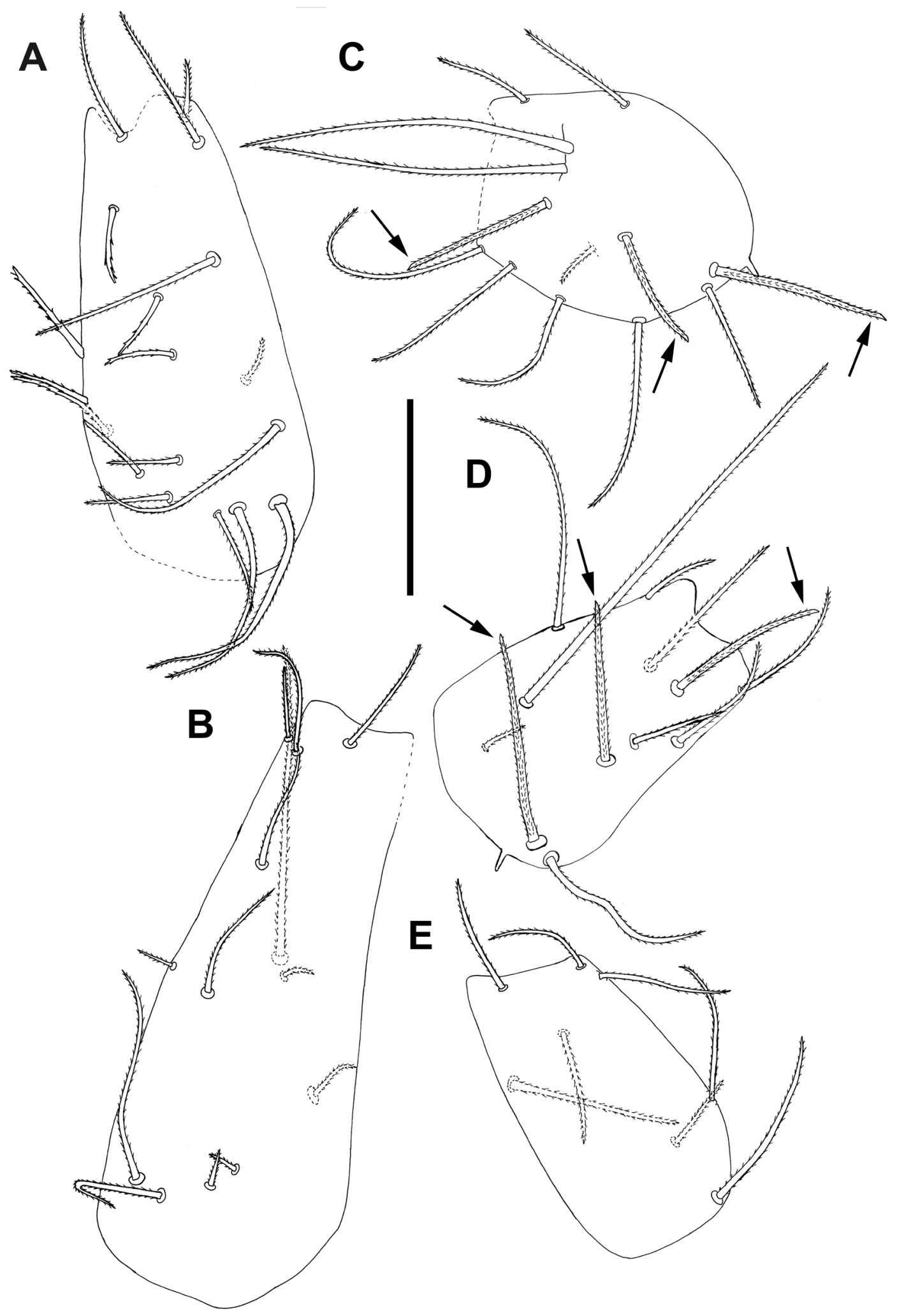

Fig. 12. Allokoenenia stygia sp. nov., ․ . A. Coxa of left pedipalp, holotype (MZSP 54247). B. Coxa of right leg I, paratype (MZSP 54249). C. Coxa of left leg II, holotype (MZSP 54247). D. Coxa of right leg III, paratype (MZSP 54249). E. Coxa of right leg IV, paratype (MZSP 54249). Scale bars $=60 \mu \mathrm{m}$. Thickened setae on coxae II, III and IV indicated by arrows. 
LEG I. $t c$ with 11 normal setae (2 considerably smaller than others); $f e$ with 9 normal setae; $p a$ with 9 normal setae and $1 t b$ (Fig. 14A); $t i$ with 9 normal setae; btal with 2 normal setae, $2 t b$ and $1 f_{s}$ (with subequal branches); bta2 with $2 \mathrm{~m}, 2$ normal setae, $2 \mathrm{tb}$ and $1 f_{s}$ (with subequal branches) (Fig. 14B); bta 3 with $1 \mathrm{r}, 1 \mathrm{grt}$ and 1 short normal seta; $b t a 4$ with $5 \mathrm{~m}, 1 \mathrm{tb}$ and 1 long $f s$; $t a l$ with 5 normal setae ( 2 considerably smaller than others); ta 2 with $5 \mathrm{~m}, 1 \mathrm{tb}$ and 1 long $f_{s}$ (Fig. 15A); ta3 with $5 f_{s}$ (with subequal branches) arranged as $f s_{I} / f_{s_{2+3}} / f_{s_{4+5}}, r s\left(r s / f s_{1}=2.4\right), 2 r, 1 \mathrm{cs}$ with conspicuous spine, $9 \mathrm{~m}$ and 9 normal setae (Fig. 15B).

LEG II. $t c$ with 3 normal setae; $f e$ with 5 normal setae; $p a$ and $t i$ with 1 thick seta and 4 normal setae each; $b t a$ with 6 normal setae; $t a$ with $1 r, 1 m$ and 9 normal setae.

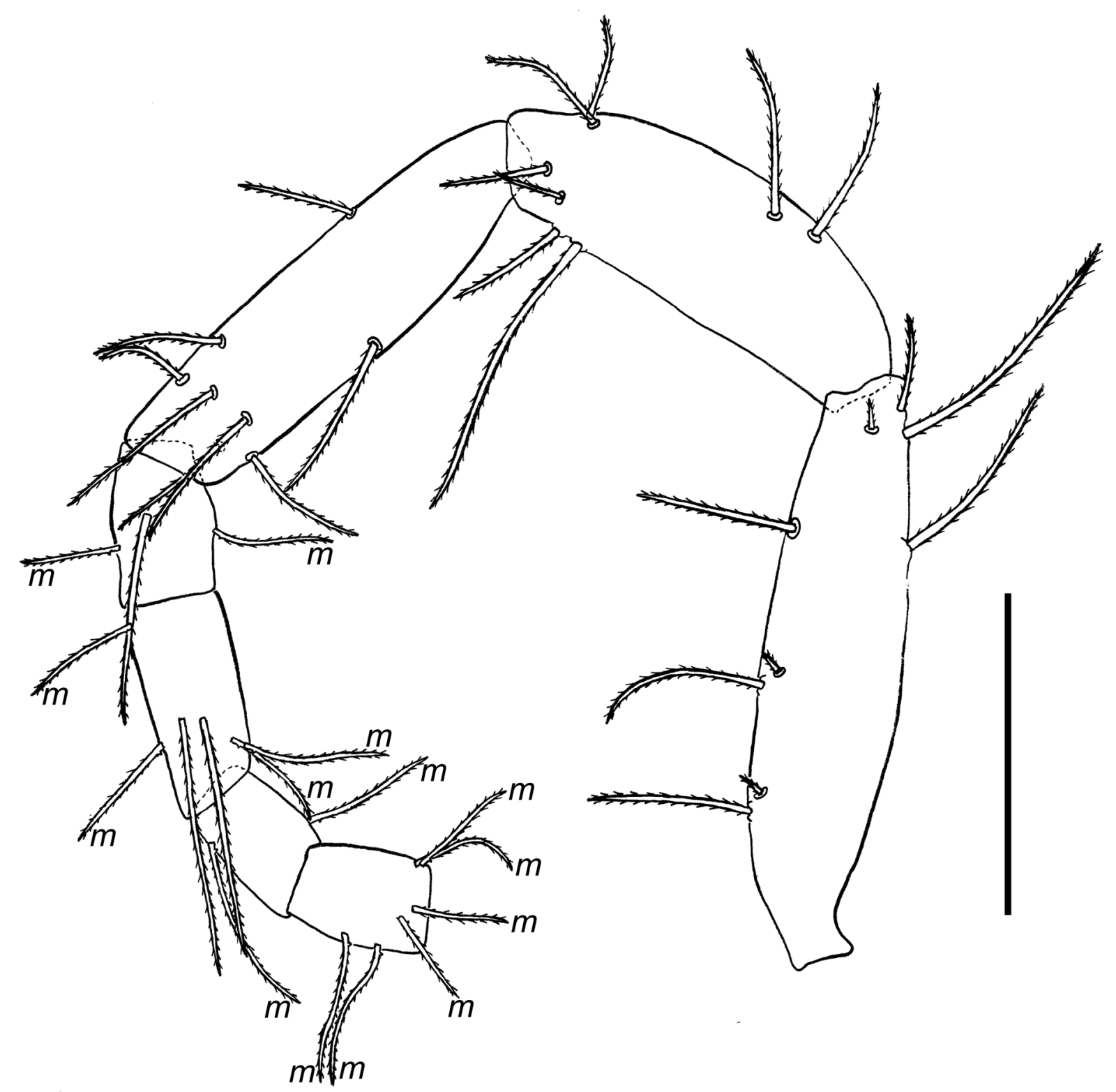

Fig. 13. Allokoenenia stygia sp. nov., + , paratype (MZSP 54249), trochanter-tarsus 2 of right pedipalp. Abbreviations: see Material and methods. Scale bar $=100 \mu \mathrm{m}$. 
LEG III. $t c$ with 2 normal setae; $f e, p a$, and $t i$ with 1 thick seta and 4 normal setae each; $b t a$ with 6 normal setae; $t a$ with $1 r, 1 m$ and 9 normal setae.

LEG IV. $t c$ with 3 normal setae; $f e$ with $1 m$ and 2 normal setae; $p a$ and $t i$ with 1 thick and 4 normal setae each; bta with grt, r, gla, esp, and 2 esd; tal with 4 normal setae; ta2 with 8 normal setae.

IV вTA. $7 \times$ longer than wide and with 6 setae $(g r t, r, g l a$, esp and 2 esd). Seta $r$ inserted around middle of article $(d r / I V b t a=0.55)$; gla inserted close to $r$ and grt inserted in proximal half (Fig. 16B).

Opisthosoma. Tergites II-VI with $2+2$ dorsal robust setae, one pair of $t$ setae $\left(t_{l}=37-50 \mu \mathrm{m}\right)$ between pair of $s$ setae $(s=25-35 \mu \mathrm{m})$ (Fig. 11E). Sternite III with $2+2$ setae. Sternites IV-VI each with $2+2$ thickened setae $\left(a_{1}=50-62 \mu \mathrm{m}, a_{2}=55-65 \mu \mathrm{m}\right)$ between pair of slender setae $(s=45-52 \mu \mathrm{m})$ (inserted caudal to thick setae); pair of pores present between $a_{1}$ setae on sternites IV-VI (Fig. 11F). In paratype, presence of inconspicuous paired cavities in intersegmental furrows between sternites III-IV, IV-V,

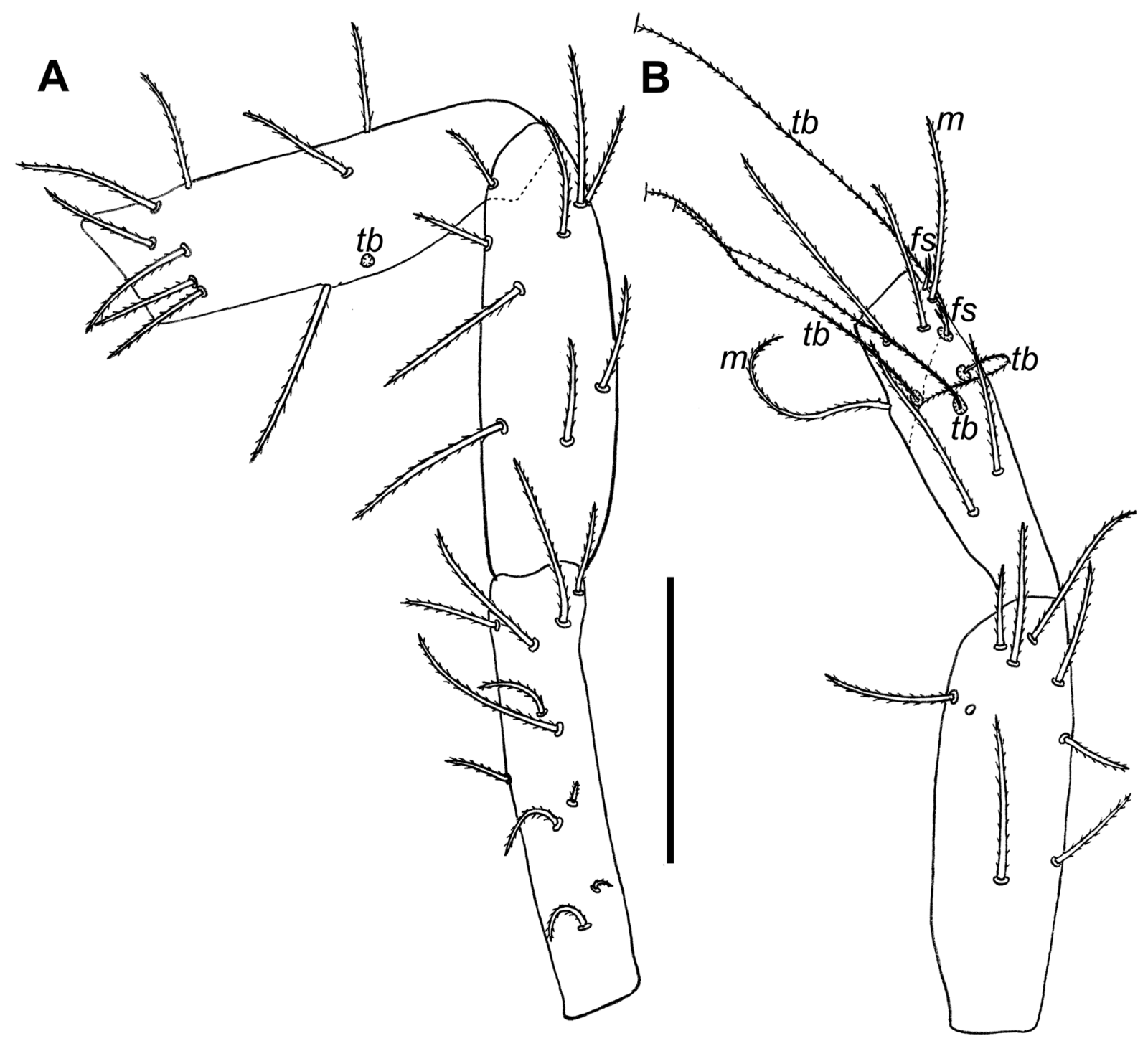

Fig. 14. Allokoenenia stygia sp. nov.,, , paratype (MZSP 54249), articles of left leg I. A. Trochanterpatella. B. Tibia-basitarsus 2. Abbreviations: see Material and methods. Scale bar $=100 \mu \mathrm{m}$. 
and V-VI, 1 at each side of opisthosoma; these cavities not observed in holotype. Segments VII-X with 8 setae each (4 dorsal and 4 ventral). Segment XI elongated (1.08-1.14 $\times$ as long as wide), with dorsal row of $2+2$ long setae (inner pair $=122 \mu \mathrm{m}$; outer pair $=112 \mu \mathrm{m}$ ) inserted around half and two pairs of ventral setae, one inserted in proximal half $(62 \mu \mathrm{m})$ and other around half $(77-82 \mu \mathrm{m})$. Intermediate ring of flagellum lost or absent in both specimens (Figs 11C, 17).

Female Genitalia. First lobe with $11+11$ setae in 5 transverse rows: $2+2$ sternal setae $\left(s t_{1}, s t_{2}\right)$ followed by $3+3,1+1,1+1$ and $4+4$ distal setae $\left(a_{1}=20 \mu \mathrm{m} ; a_{2}=25 \mu \mathrm{m} ; a_{3}=30 \mu \mathrm{m} ; a_{4}=37 \mu \mathrm{m}\right)$; interior surface of first lobe with group of 3 orifices on either side and medial pair of small orifices (Fig. 18A). Second lobe with $3+3$ setae $(x=10-11 \mu \mathrm{m} ; y=35-37 \mu \mathrm{m} ; z=25-34 \mu \mathrm{m})$, and with cuticular spines; presence of group of 4 orifices on each half (Fig. 18B).

Flagellum. Not preserved.

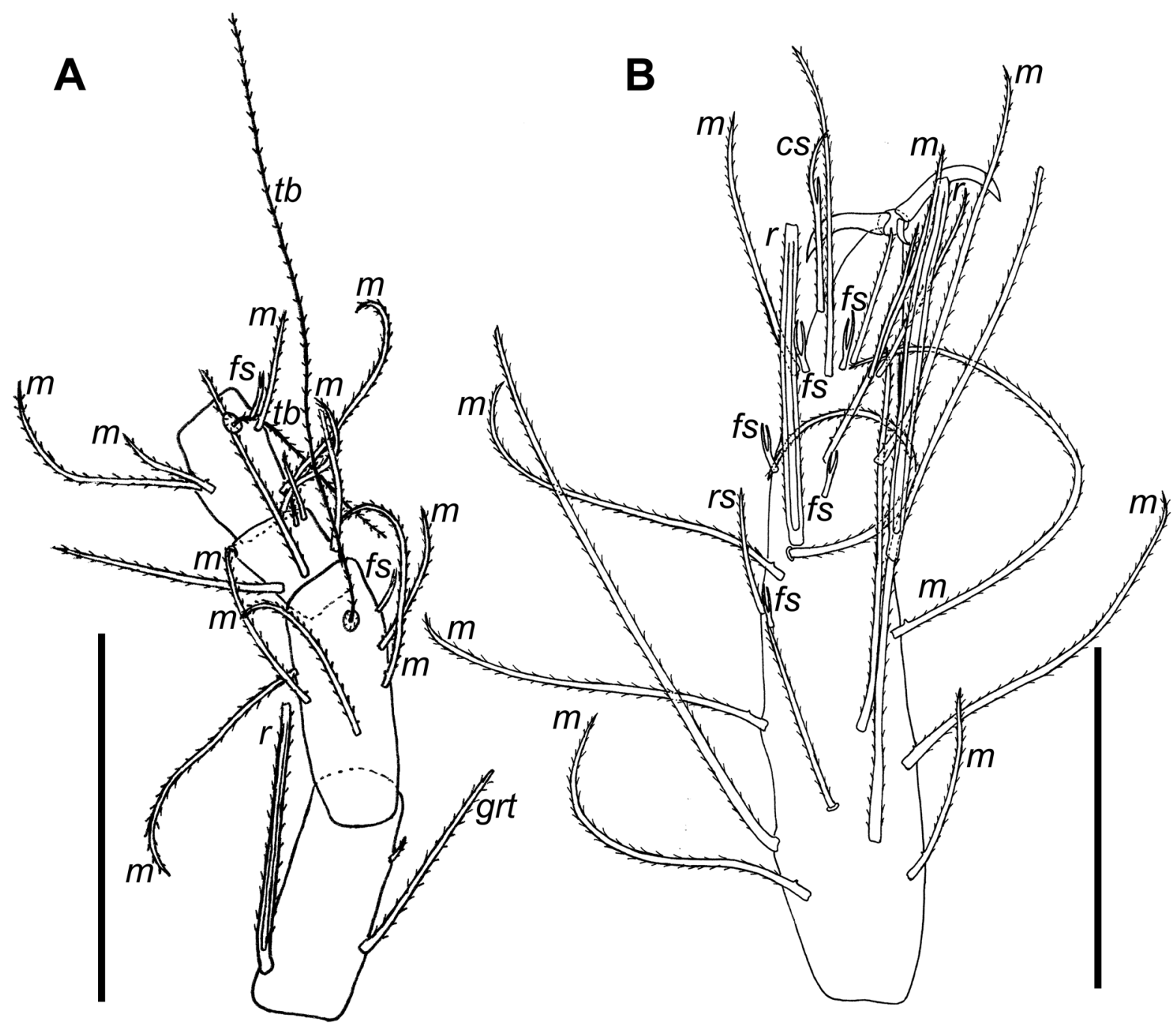

Fig. 15. Allokoenenia stygia sp. nov., +, paratype (MZSP 54249), articles of left leg I. A. Basitarsus 3-tarsus 2. B. Tarsus 3. Abbreviations: see Material and methods. Scale bars: A $=100 \mu \mathrm{m} ; \mathrm{B}=60 \mu \mathrm{m}$. 


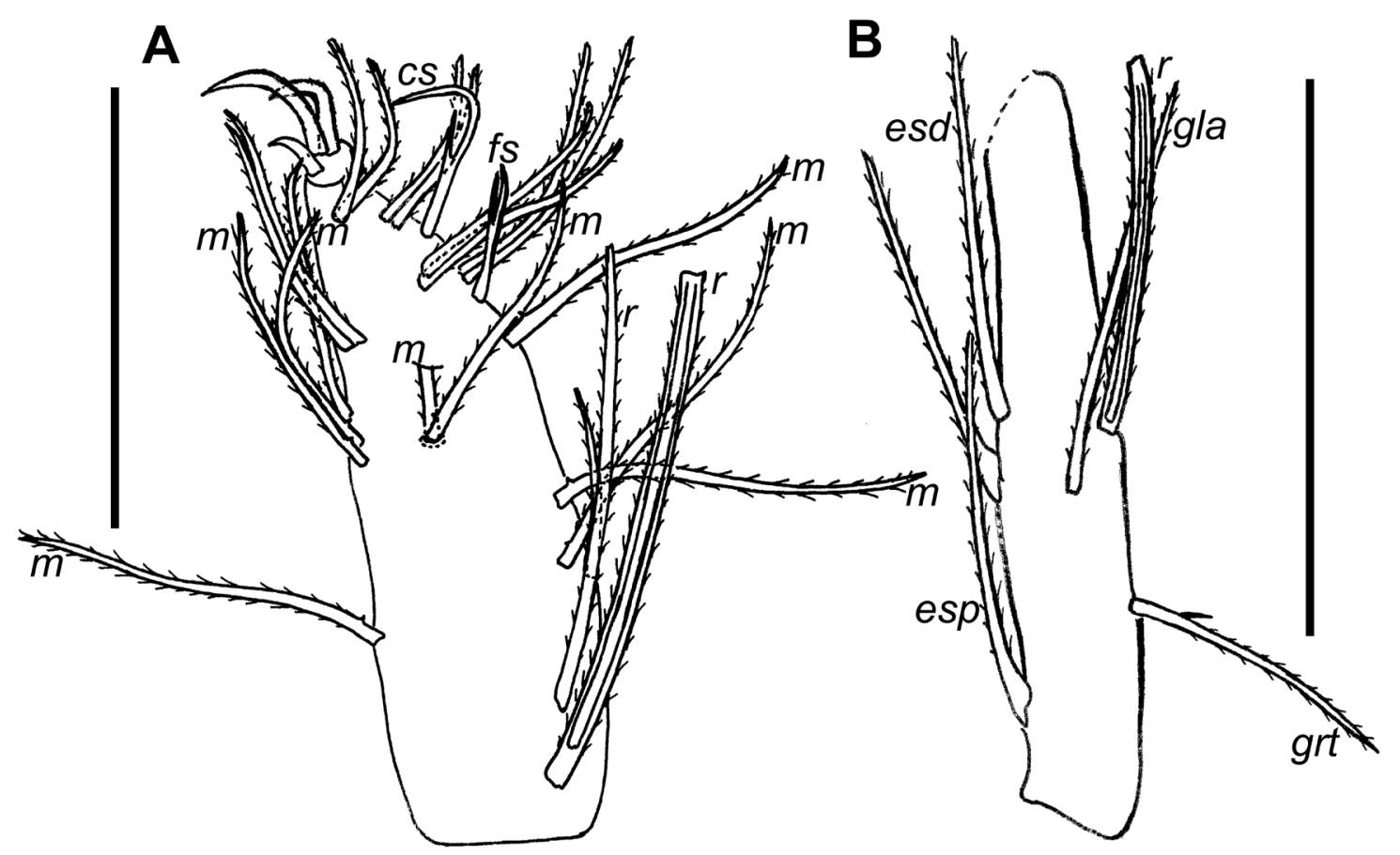

Fig. 16. Allokoenenia stygia sp. nov., + , paratype (MZSP 54249). A. Tarsus 3 of right pedipalp. B. Basitarsus of left leg IV. Abbreviations: see Material and methods. Scale bars: A $=40 \mu \mathrm{m} ; \mathrm{B}=100 \mu \mathrm{m}$.

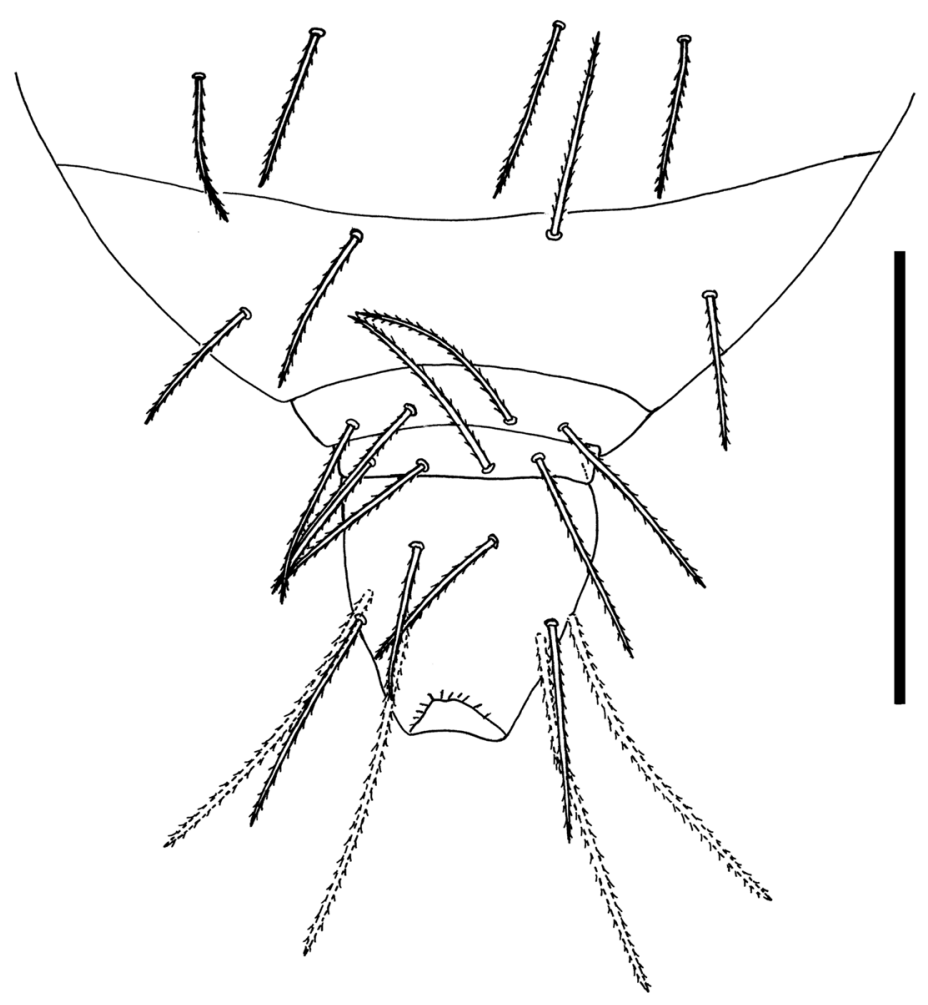

Fig. 17. Allokoenenia stygia sp. nov., + , holotype (MZSP 54247), opisthosomal segments VII-XI, ventral view (the dorsal setae of segment XI is also illustrated, represented in dashed line). Scale bar $=150 \mu \mathrm{m}$. 


\section{Male and immatures}

Unkown.

\section{Distribution}

Known only from SB_0114 and SB_0112 caves (municipality of Canaã dos Carajás, Pará State, Brazil).

\section{Remarks}

Allokoenenia stygia sp. nov. fits the diagnosis of Allokoenenia by the relative width of the last opisthosomal segments. The flagellum was lost during the collection and therefore its morphology remains unknown. As with A. afra, A. canhembora sp. nov., and Allokoenenia sp., the ventral setae on the last opisthosomal segment of this new species is arranged in two rows.

Allokoenenia stygia sp. nov. differs from A. afra by the shape of frontal organ (Figs 1C, 10A), and by the number of blades on lateral organs ( 3 vs 1 ) and deutotritosternal setae (5 vs 1) (Silvestri 1913). Considering the new congeneric species herein described, A. stygia sp. nov. differs from both by presenting the two most proximal setae on cheliceral hand thickened, the $c s$ seta of leg I with a conspicuous spine, trochanter of leg I with 11 setae (vs 12 setae), coxa I with 13 setae (vs 15), coxa IV without thick seta (vs one seta), a single pair of $t$ setae on opisthosomal tergites II-VI (vs two pairs), 6 setae on bta IV (vs 5 setae) and 3 blades on lateral organs (vs 4 in Allokoenenia sp. and 5 in A. canhembora sp. nov.). Additionally, the new species can be distinguished from A. canhembora sp. nov. by having 2 pairs of thickened setae (a) on opisthosomal sternites IV-VI (vs 3 pairs) and 11 pairs of setae on the first lobe of female genitalia (vs 10 pairs).

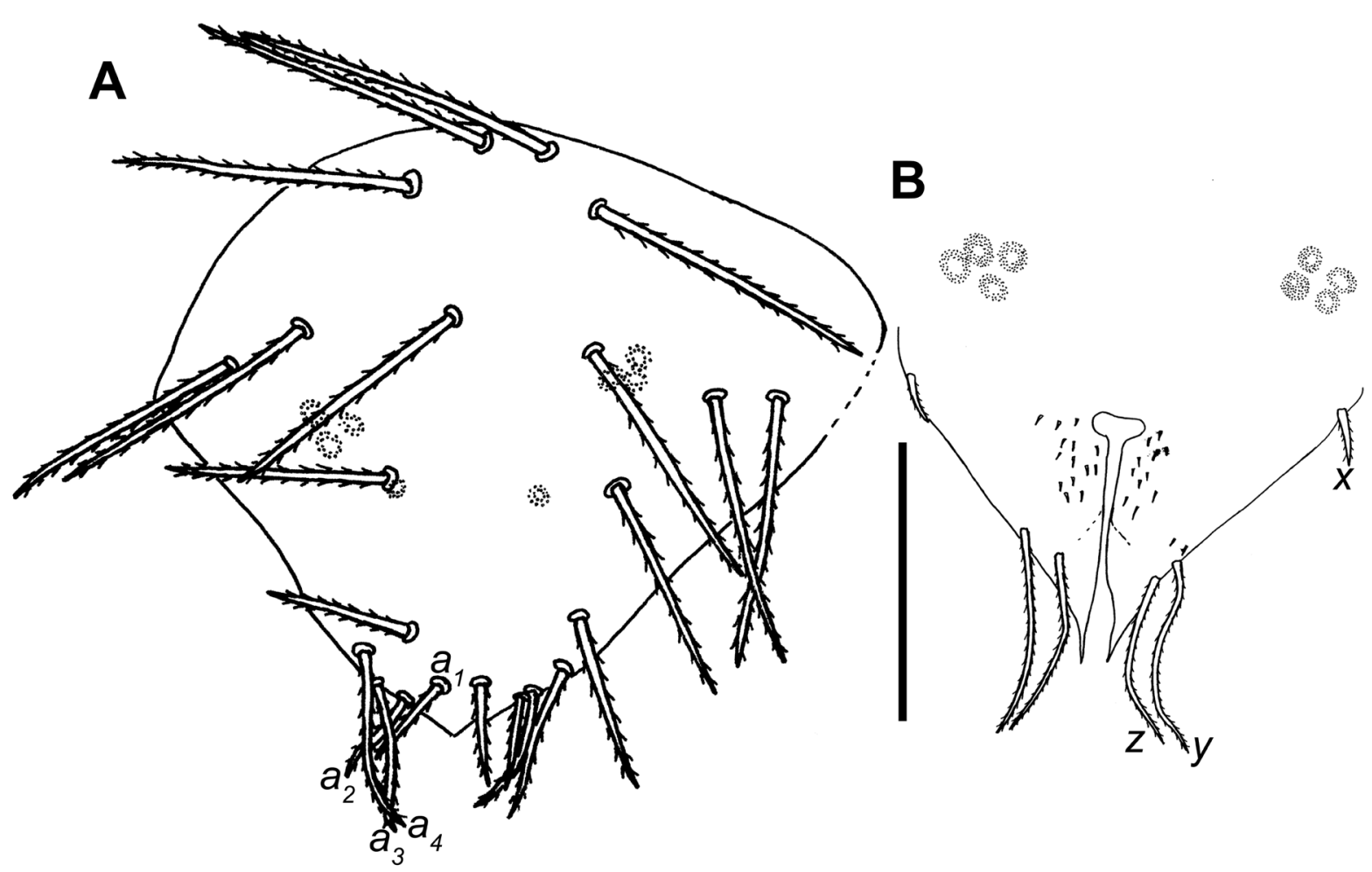

Fig. 18. Allokoenenia stygia sp. nov.,, , paratype (MZSP 54249). A-B. First and second lobes of female genitalia, respectively. Abbreviations: see Material and methods. Scale bar $=50 \mu \mathrm{m}$. Dotted circles and elipses represent cuticular orifices. 

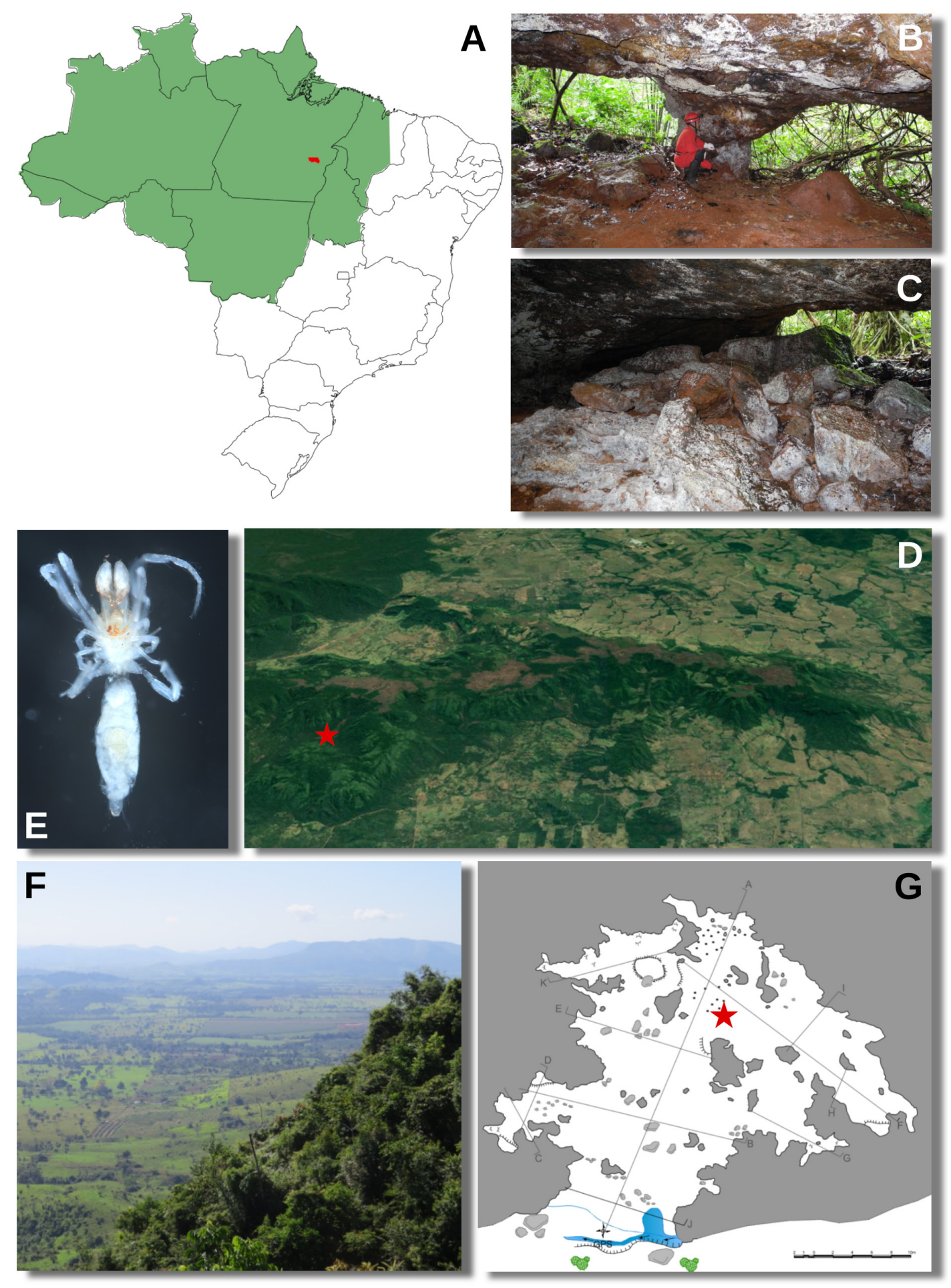

Fig. 19. Allokoenenia stygia sp. nov. A. Map of Brazil showing the placement of the Amazonia Biome, delimited in green, and of the SB_0114 and SB_0112 caves (in red). B-C. Inner portions of the single conduit that forms the SB_0114 cave, type locality of A. stygia sp. nov. D. Serra da Bocaina, with the placement of the two caves where the new species occurs indicated by a red star. E. Habitus of the paratype (MZSP 54249) under a stereo microcope before mounting. F. Landscape in the surroundings of Serra da Bocaina, showing the presence of pastures. G. Plan view of SB_0114 cave (type locality), showing the palpigrade collecting site (red star). 


\section{Habitat and threats}

Individuals of Allokoenenia stygia sp. nov. (Fig. 19E) were found in two adjacent iron ore caves (about $90 \mathrm{~m}$ bee-line from each other) located in a ferruginous plateau known as Serra da Bocaina (Fig. 19D), inserted in the domain of Amazon Forest (Fig. 19A), Northern Brazil. Other caves in this region were sampled, but no specimens of this species were found at other localities. These two caves, named SB_0114 (Figs 19B-C) and SB_0112, have horizontal projections of 89 and $16.1 \mathrm{~m}$, respectively, and are formed by a single spongiform gallery (Fig. 19G). In 2017, a National Park was created (Parque Nacional dos Campos Ferruginosos) incorporating the Serra da Bocaina region. This conservation unit has $790.9 \mathrm{~km}^{2}$ and protects two important iron ore formations within the Carajás geological province: the Serra da Bocaina and the Serra do Tarzan. However, although the top and the slopes of those plateaus are preserved, most of the area (especially in the surroundings of the Serra da Bocaina) is very altered by human activities (especially pastures) (Fig. 19D, F). Fortunately, the area where the SB_0112 and SB_0114 caves are located is preserved. At the same time, despite the recently created conservation unit, frequent criminal fires hit the region, often advancing over the forest. Such fires usually come from conflicts between the local farmers and landless people, and such impacts may represent a threat for the species, especially when considering its very restricted distribution.

\section{Allokoenenia sp.}

Figs 20-25

\section{Material examined}

BRAZIL • 1 juvenile 9 ; Bahia, Ourolândia, Toca dos Ossos Cave; 1055'51.31" S, 41³'27.22" W; 571 m a.s.1.; 12 Jun. 2012; R.L. Ferreira leg.; ISLA 50396.

\section{Description}

\section{Immature female}

Measurements And Ratios. See Table 2.

Prosoma. Frontal organ formed by two reticulated and expanded branches ( $33 \mu \mathrm{m}$ long), with pointed tips (Fig. 20A). Lateral organ with 4 blades pointed-lanceolate $(25 \mu \mathrm{m}$ long) and finely reticulated (Fig. 20B). Propeltidium with $7+7$ short setae (Fig. 20C). Metapeltidium with $3+3$ setae of similar lengths $\left(t_{1}=t_{2}=65 \mu \mathrm{m} ; t_{3}=62 \mu \mathrm{m}\right)$ (Fig. 21D). Deuto-tritosternum with 3 setae in U-shaped arrangement (Fig. 21A). Labrum with $4+4$ short setae. Basal segment of chelicera 175 long (dorsal length), with 6 proximal setae ( $p_{4}$ and $p_{6}$ thickened and densely barbed; $p_{1}$ slightly thinner and barbed) (Fig. 21B), and 3 distal setae: $d_{3}(85)$ longer than $d_{1}(47)$ and $d_{2}(50) ; d_{3}$ smooth near base and barbed in distal half, $d_{1}$ and $d_{2}$ thin, flexible and with tiny projections in the apex (Fig. 21C); and one apical seta. Hand of chelicera with 6 setae: 3 dorsal setae, 2 setae in outer portion ( 1 close to articulation of movable finger and 1 on tubercle close to teeth of fixed finger) and 1 seta inserted in inner portion. Fingers with 8 teeth each.

Coxal chaetotaxy. Pedipalp coxa with 17 setae (Fig. 20D); coxa I with 13 ordinary setae and two microsetae (Fig. 20E); coxa II with 3 thick setae, two macrosetae, and 8 ordinary setae (Fig. 20F); coxa III with 3 thick setae, one macroseta, and 8 ordinary setae (including one small seta adjacent to the macroseta) (Fig. 20G) and coxa IV with 1 thick and 8 ordinary setae (Fig. 20H).

PediplaP. $t c$ with 8 setae ( 2 considerably smaller than others); $f e$ with 8 setae; $t i$ with 8 setae (Fig. 22A); btal with $2 \mathrm{~m}$ and 1 normal seta; bta2 with 1 normal seta and $5 \mathrm{~m}$ (Fig. 22B); tal with $2 \mathrm{~m}$; ta2 with $6 \mathrm{~m}$; ta3 with 1 long $f_{s}, 1 \mathrm{cs}$ with conspicuous spine, $2 \mathrm{r}, 14 \mathrm{~m}$ (1 macroseta with basal denticle and conspicuous spine) and 6 normal setae (Fig. 22C). 


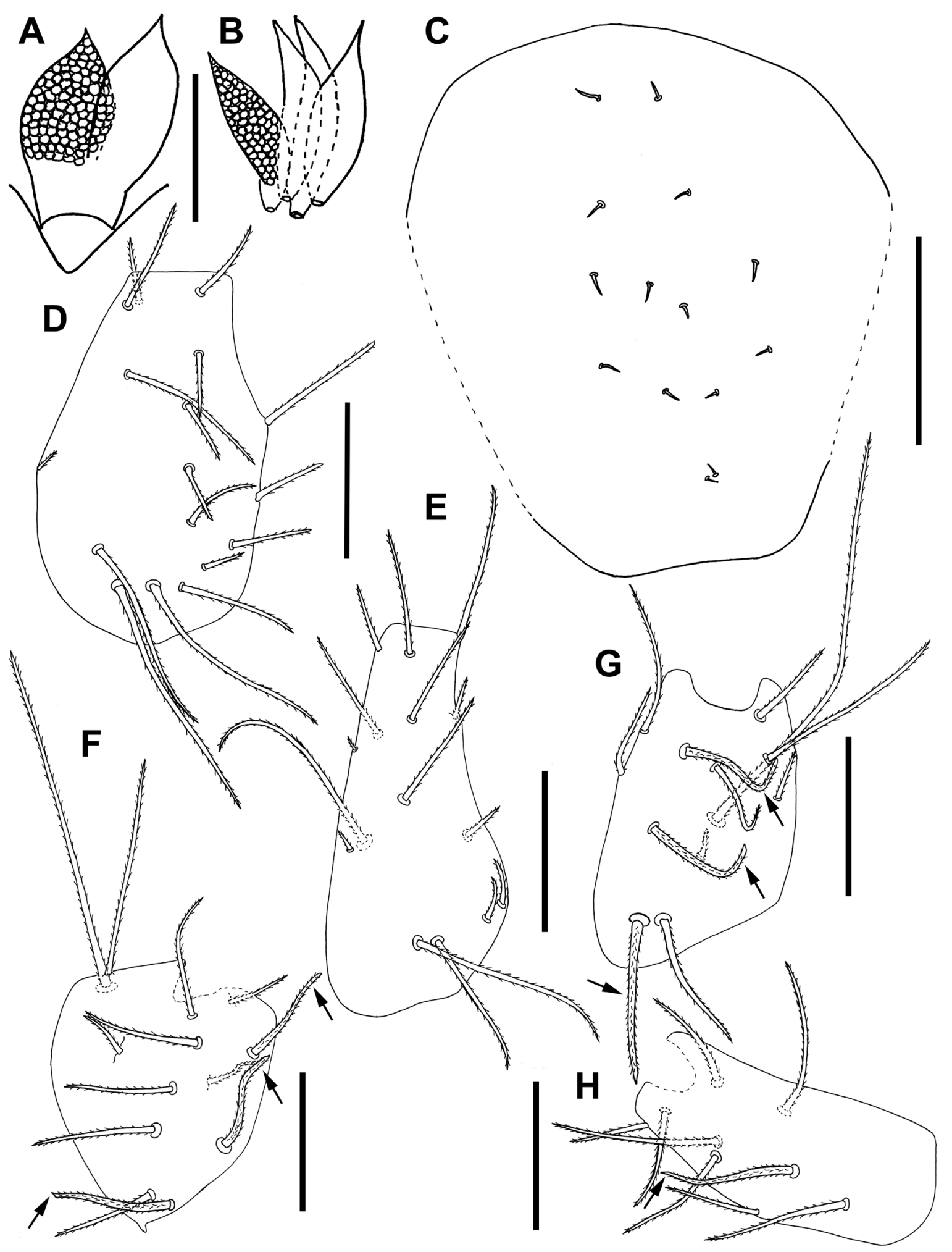

Fig. 20. Allokoenenia sp., juvenile $q$ (ISLA 50396). A. Frontal organ. B. Blades of lateral organ. C. Propeltidial chaetotaxy. D. Coxa of right pedipalp. E. Coxa of right leg I. F. Coxa of left leg II. G. Coxa of right leg III. H. Coxa of left leg IV. Scale bars: A-B $=20 \mu \mathrm{m} ; \mathrm{C}=100 \mu \mathrm{m} ; \mathrm{D}-\mathrm{H}=40 \mu \mathrm{m}$. Thickened setae on coxae II-IV indicated by arrows. 
LEG I. $t c$ with 12 normal setae ( 2 considerably smaller than others); $f e$ with 9 normal setae; $p a$ with 9 normal setae and $1 \mathrm{tb}$; $t i$ with 9 normal setae (Fig. 23A); btal with $1 \mathrm{~m}, 1$ normal seta, $2 \mathrm{tb}$ and $1 \mathrm{fs}$ (with inner branch shorter than outer branch); bta 2 with $4 \mathrm{~m}, 2 \mathrm{tb}$ and 1 long $f s ; b t a 3$ with $1 \mathrm{r}, 1 \mathrm{grt}$ and 1 short normal seta; bta 4 with $5 \mathrm{~m}, 1 \mathrm{tb}$ and 1 long $f_{s}$; tal with 5 normal setae ( 2 considerably smaller than others); ta 2 with $5 \mathrm{~m}, 1 \mathrm{tb}$ and 1 long $f_{s}$ (Fig. 23B); ta3 with $5 f_{s}$ (with subequal branches) arranged as $f_{s_{l}} / f_{s_{2+3}} / f_{s_{4+5}}, r s$ ( $\left.r s / f_{s_{l}}=1.8\right), 2 r, 1 \mathrm{cs}, 13 \mathrm{~m}$ and 5 normal setae (Fig. 23C).

IV втA. $5.5 \times$ as long as wide and with 5 setae (grt, $r$, esp and 2 esd). Seta $r$ inserted in distal half $(d r)$ $I V b t a=0.66)$ and grt inserted in proximal half of segment (Fig. 23D).

Opisthosoma. Tergites II-V with $3+3$ dorsal setae, two pairs of $t$ setae $\left(t_{1}=27-35 \mu \mathrm{m}, t_{2}=27-35 \mu \mathrm{m}\right)$ between pair of slender setae $(s=20-25 \mu \mathrm{m})$ (Fig. 21E). Tergite VI with $3+2$ setae (asymmetry caused by lack of one $t$ seta). Sternite III with $2+2$ setae. Sternites IV-VI each with $2+2$ thickened setae $\left(a_{1}=37 \mu \mathrm{m}, a_{2}=40-45 \mu \mathrm{m}\right)$ between pair of slender setae $(s=25 \mu \mathrm{m})$ (inserted caudal to thick setae); pair of pores present between $a_{1}$ setae on sternites IV-VI. It was not possible to observe paired cavities in intersegmental furrows between sternites III-VII. Since the opisthosoma of this specimen was ruptured during the mounting process, it is not possible to determine wether these cavities are absent
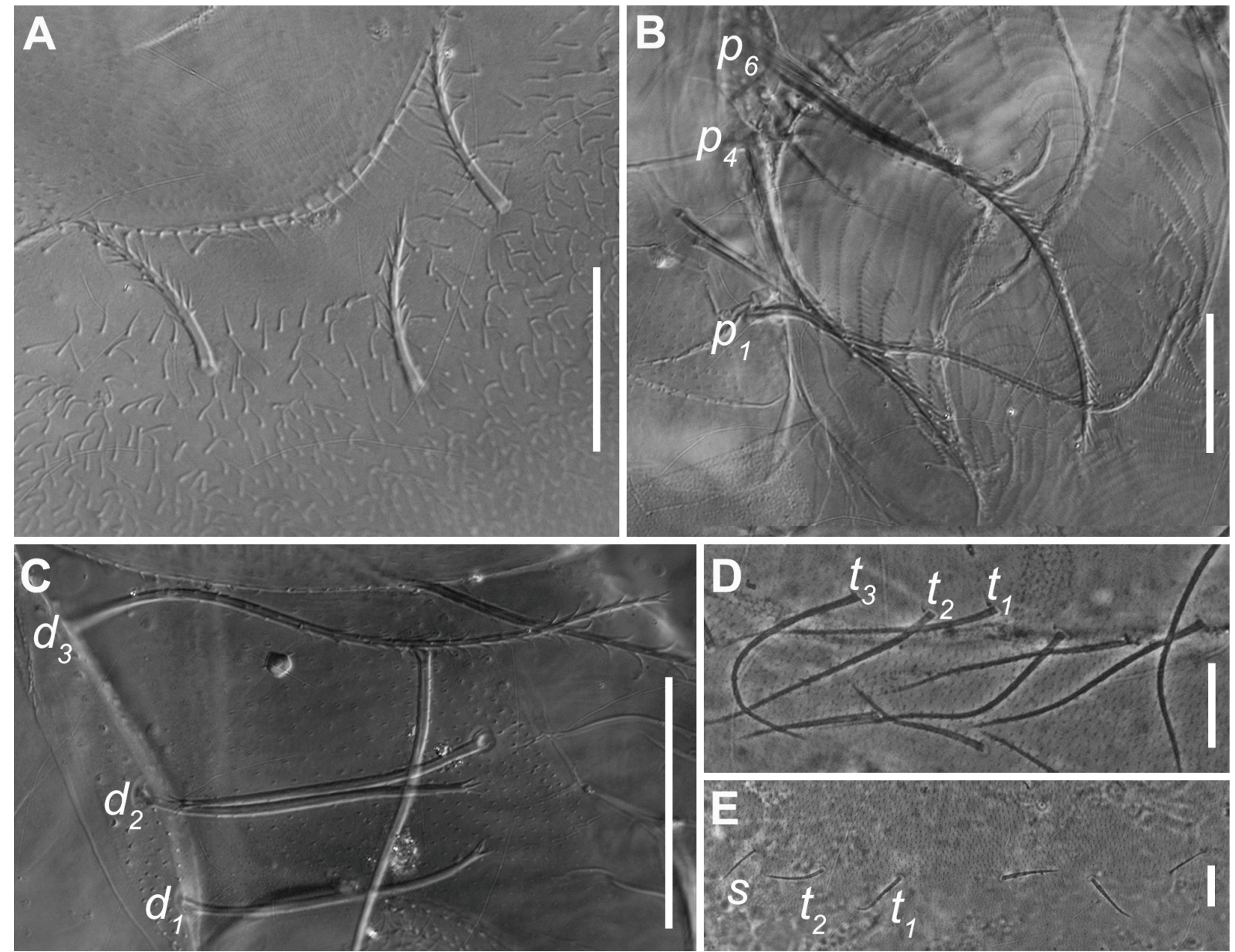

Fig. 21. Allokoenenia sp., juvenile $q$ (ISLA 50396). A. Deutotritosternal setae. B. Proximal setae ( $p_{I}-$ $p_{6}$ ) on basal segment of chelicera. C. Distal setae $\left(d_{1}-d_{3}\right)$ on basal segment of chelicera. D. Metapeltidial chaetotaxy. E. Chaetotaxy of opisthosomal tergite III. Abbreviations: see Material and methods. Scale bars: A-B, D-E $=20 \mu \mathrm{m} ; \mathrm{C}=40 \mu \mathrm{m}$. 
or not interpretable. Segments VII-X with 8 setae each (4 dorsal and 4 ventral). Segment XI elongated $(1.37 \times$ as long as wide), with dorsal row of $2+2$ long setae (inner pair $=140 \mu \mathrm{m}$; outer pair $=100 \mu \mathrm{m})$ inserted in distal half and two pairs of ventral setae, one inserted around middle of segment $(50 \mu \mathrm{m})$ and other inserted in apical region $(55 \mu \mathrm{m})$ (Fig. 24A). Intermediate ring of flagellum reduced in size $(11 \mu \mathrm{m})$ with membranous aspect, with cuticular spines and without setae (Fig. 24A).

Primordia of GeNital lobes. Anterior genital lobe on sternite II with simple median indentation and 2 spines in its distal margin, and with $4+4$ setae arranged in 3 transverse rows: proximal pair of setae, followed by $2+2$ setae and more distally by pair of shorter median setae, corresponding to "type 1 " described by Condé (1984). Posterior lobe on sternite III formed by two rounded halves, each with 1 spine and 1 tiny seta laterally inserted (Fig. 24B).

Flagellum. Not preserved.

\section{Adults, immature male and larva}

Unkown.

\section{Distribution}

Known only from Toca dos Ossos Cave.

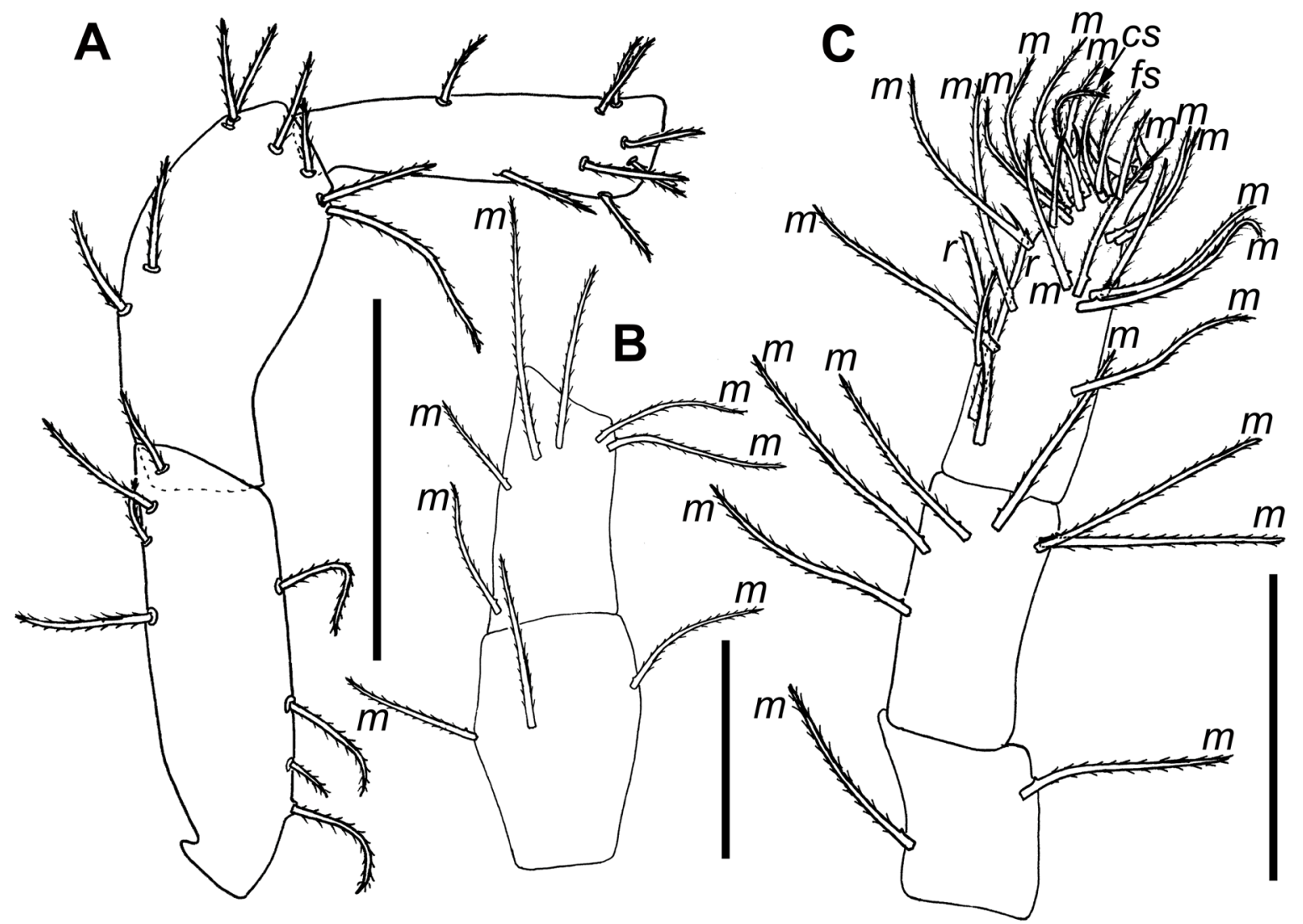

Fig. 22. Allokoenenia sp., juvenile + (ISLA 50396), left pedipalp. A. Trochanter-tibia. B. Basitarsi 1-2. C. Tarsi 1-3. Abbreviations: see Material and methods. Scale bars: A $=100 \mu \mathrm{m} ; \mathrm{B}-\mathrm{C}=40 \mu \mathrm{m}$. 


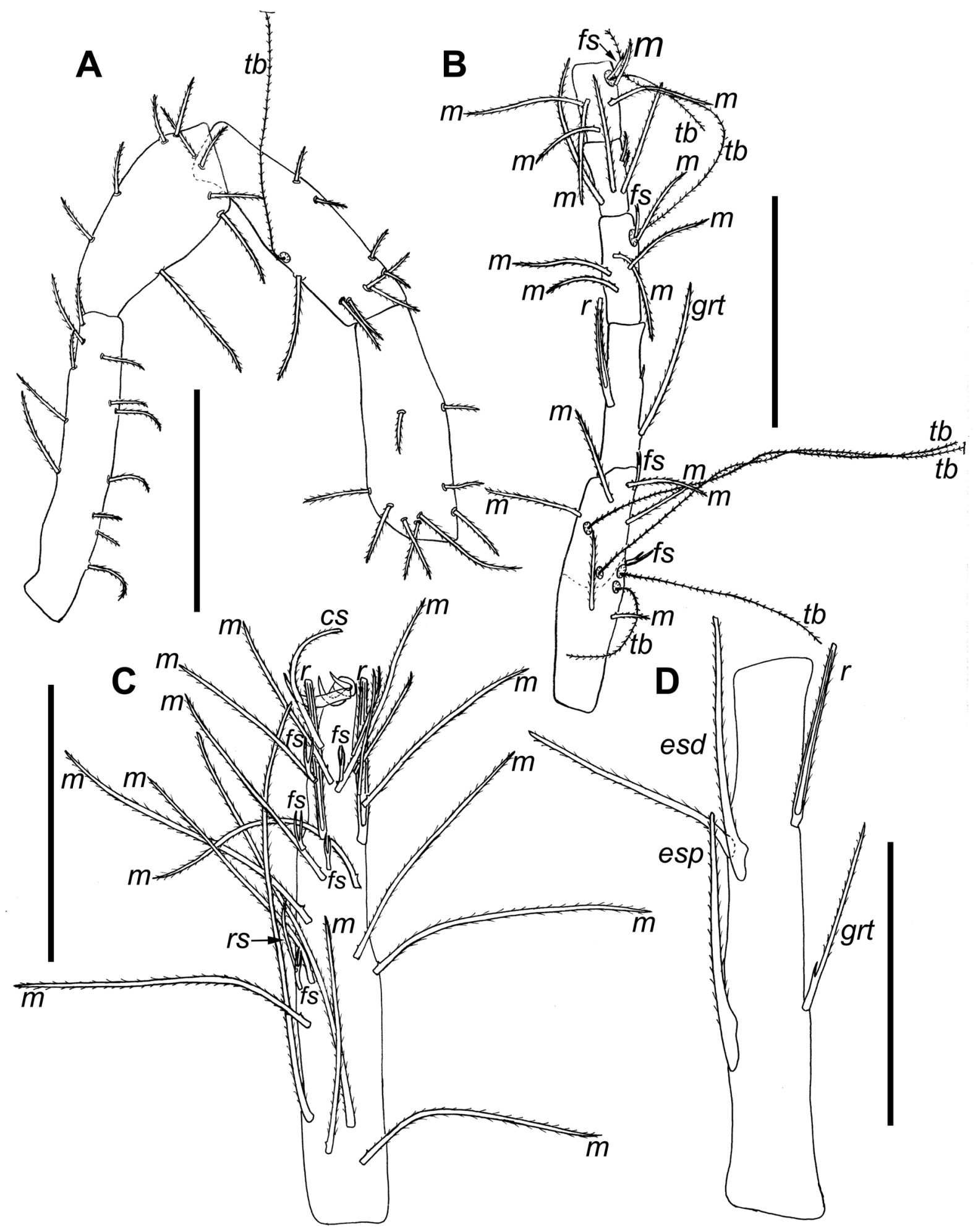

Fig. 23. Allokoenenia sp., juvenile $q$ (ISLA 50396), left pedipalp. A. Trochanter-tibia of right leg I. B. Basitarsi 1-tarsus 2 of right leg I. C. Tarsus 3 of left leg I. D. Basitarsus of right leg IV. Abbreviations: see Material and methods. Scale bars: A-B $=100 \mu \mathrm{m} ; \mathrm{C}-\mathrm{D}=60 \mu \mathrm{m}$. 


\section{Remarks}

Allokoenenia sp. can be assigned to this genus by the relative width of the last opisthosomal segments. Unfortunately, the flagellum was lost during collection, which precludes to determine whether the arrangement of the flagellar features is in accordance with the diagnosis of the genus.

This species shares with $A$. afra the arrangement of ventral setae on the last opisthosomal segment (distributed in two rows). However, even though represented by a single immature specimen, it can be readily distinguished from $A$. afra by the shape of the frontal organ (Figs 1C, 20A), and by the number of blades on lateral organs (4 vs 1) and deutotritosternal setae (3 vs 1) (Silvestri 1913), as well as by the chaetotaxy of basitarsus IV ( 5 vs 6 setae). The chaetotaxy of opisthosomal sternites IV-VI is an additional difference, since the immature of $A$. afra has three pairs of thickened setae, while this species has only two pairs.

Allokoenenia sp. is very similar to A. canhembora sp. nov., since they share most of their diagnostic features. The main differences observed in the specimens from these two localities are the number of thick setae ( $a$ ) on opisthosomal sternites IV-VI ( 2 vs 3 pairs), the blades on the lateral organs (4 vs 5), the setae on the palpal coxae (17 vs 18), the setae on the cheliceral hand (6 vs 7), the deutotritosternal setae (3 vs 5), and the cheliceral teeth ( 8 vs 9 ). However, as the number of setae in these body parts and of cheliceral teeth tends to increase during ontogeny, these differences are presumably related to the fact that Allokoenenia sp. is represented by an immature specimen. Other characteristics that are most likely to actually correspond to morphological differences between these two specimens are the shape of the intermediate ring of the flagellum and opisthosomal segment XI. The intermediate ring of the flagellum is very rudimentary in Allokoenenia sp., resembling more a membranous structure with cuticular spines,

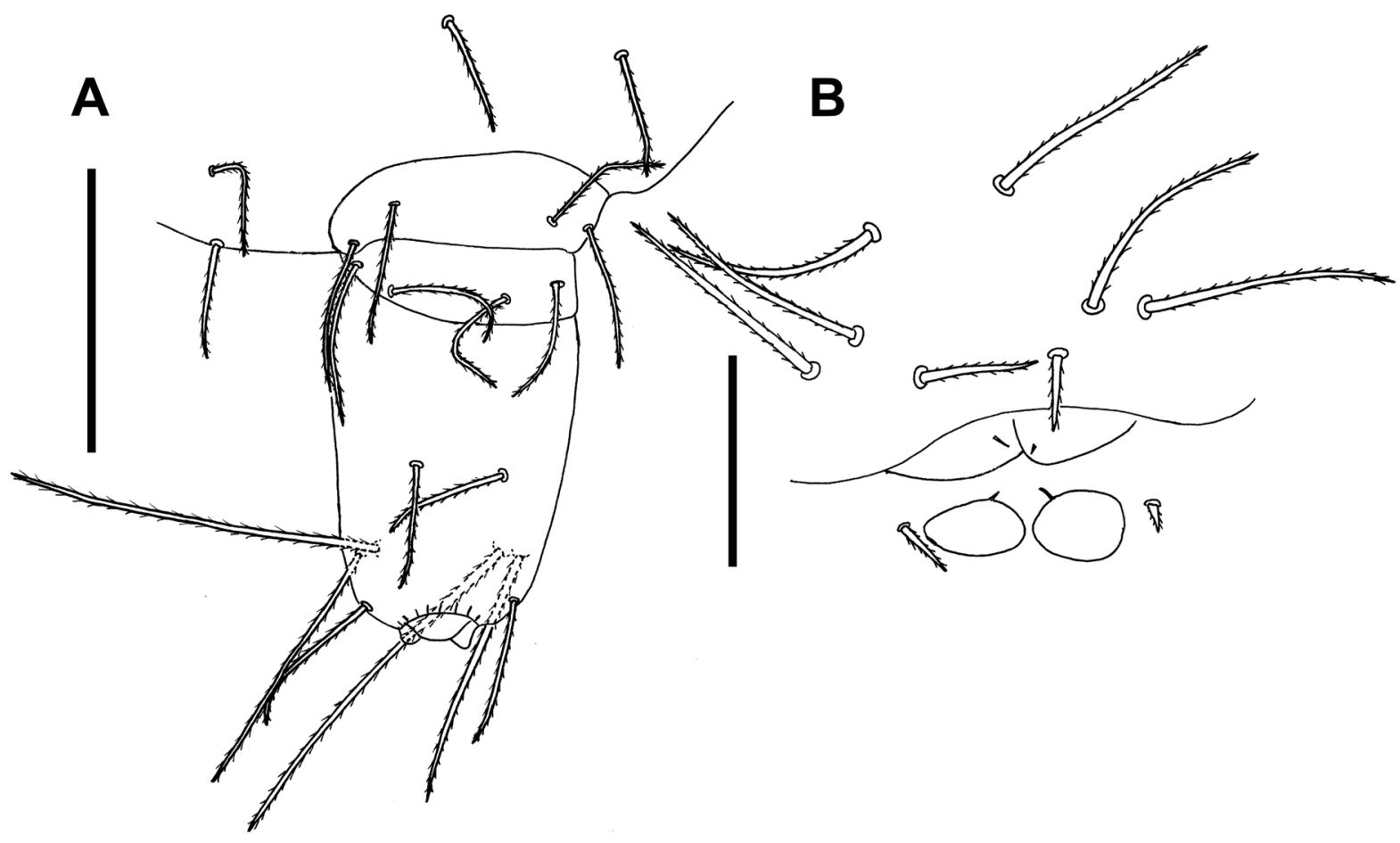

Fig. 24. Allokoenenia sp., juvenile $q$ (ISLA 50396). A. Opisthosomal segments VIII-XI, ventral view (the dorsal setae of segment XI are also illustrated, with their insertions represented in dashed lines). B. Primordia of genital lobes of immature B. Scale bars: A $=100 \mu \mathrm{m} ; \mathrm{B}=30 \mu \mathrm{m}$. 

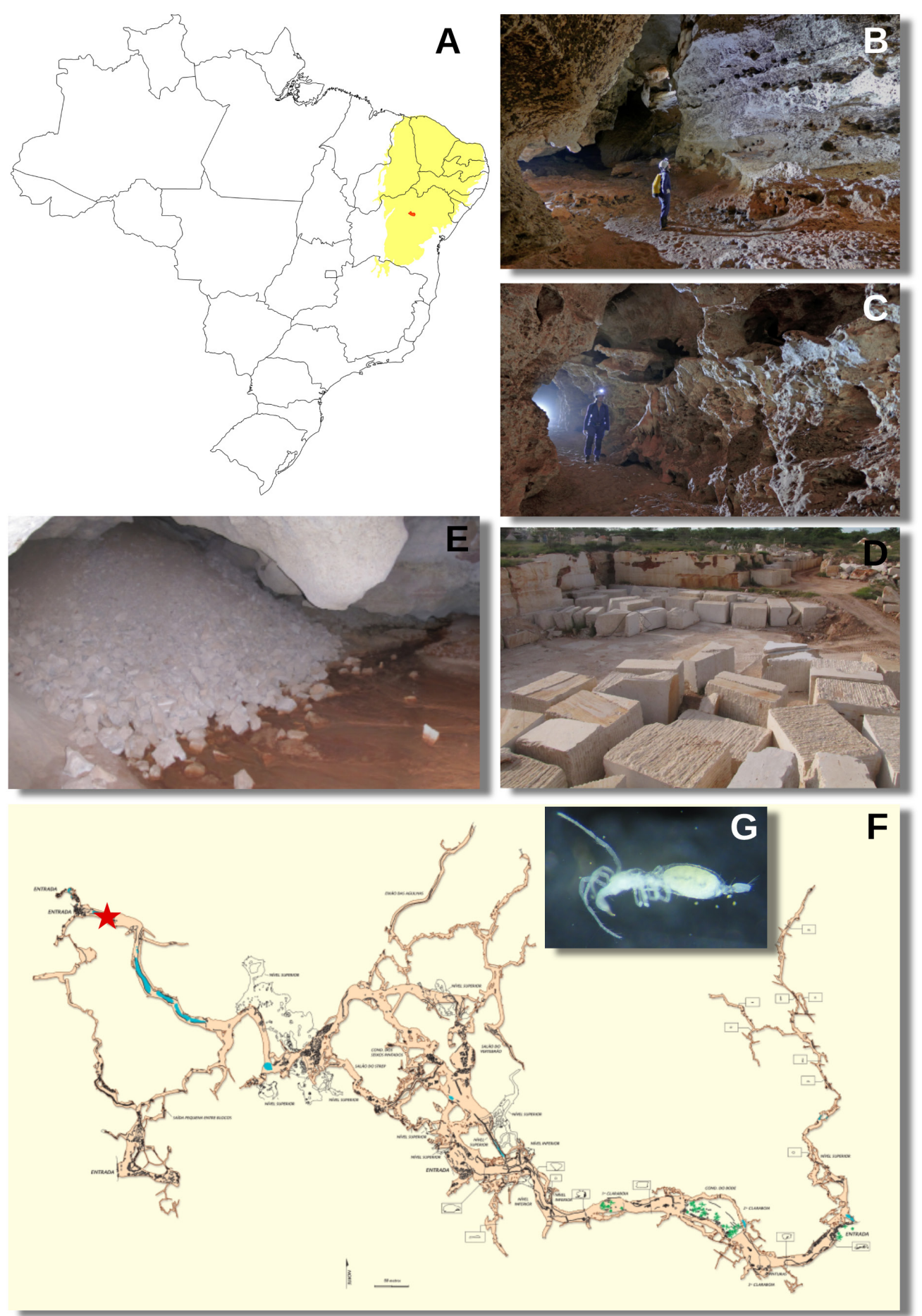

Fig. 25. Allokoenenia sp. A. Map of Brazil showing the placement of the Caatinga Biome, delimited in yellow, and of Toca dos Ossos Cave (in red), habitat of Allokoenenia sp. B-C. Galleries of Toca dos Ossos Cave, showing its spongiform architecture. D. Surrounding landscape outside the Toca dos Ossos Cave, showing the limestone quarry that operated above the cave for many years. E. Area of Toca dos Ossos covered by rock fragments transported to the cave in consequence of the quarrying activities. F. Plan view of Toca dos Ossos, showing the structure of the cave with vadose galleries connected by a complex of labyrinthine smaller conduids; the palpigrade collecting site is indicated by a red star. G. Habitus of Allokoenenia sp., $q$ (ISLA 50396) under a stereo microcope before mounting. 
without any seta. In A. canhembora sp. nov. it is slightly more developed and bears two short setae. It is noteworthy that differences in the shape of this structure have never been reported in conspecific specimens in different stages of development. In addition, the last opisthosomal segment is slightly longer in Allokoenenia sp. than in A. canhembora sp. nov. (1.37 vs $1.15 \times$ as long as wide).

The caves where Allokoenenia sp. and A. canhembora sp. nov. occur are located in the North of Bahia State (approximately $50 \mathrm{~km}$ bee-line from each other), in the domain of the Brazilian Caatinga, which is a semi-arid biome. Considering that palpigrades are fairly dependent on high humidity, the establishment of populations of these two species in endogenous habitats in this region is apparently unviable due to unsuitable climatic conditions. However, even with the previously mentioned morphological differences, and the low probability of connection between these two populations, the fact that the only specimen known from Toca dos Ossos is immature prevents us from ruling out conspeficity. Accordingly, we described the morphology of this immature specimen in order to register the presence of a troglomorphic species of this genus in Toca dos Ossos, since several visits to the cave after its discovery failed in finding additional specimens. We highlight the need of future efforts to capture new specimens, including adults. This will allow us to conclude whether or not this species is morfologically different from A. canhembora sp. nov.

\section{Habitats and threats}

The Toca dos Ossos Cave comprises the eighth largest cave in Brazil, with $14.2 \mathrm{~km}$ of topographed galleries. It is inserted in limestones from the Caatinga geological group (the same from the Toca do Gonçalo Cave), within the Caatinga Biome (Fig. 25A). The cave presents an extremely complex spongiform architecture, and although there are some vadose galleries conforming the main conduits of the cave (Fig. 25B-C), such galleries are connected to a complex of small labyrinthic conduids (Fig. 25F). The cave is extremely dry, and some water ponds are only formed during strong rains in the region, which are quite rare. The main organic resources occurring in the cave are guano piles deposited by bats, especially frugivorous and omnivorous species. Large bat colonies can persist for a long time in some areas inside the cave. One of the authors (RLF) observed such colonies sheltering at the same areas over the last 24 years, what indicates their fidelity to the roost sites.

The single specimen of Allokoenenia sp. (Fig. 25G) was found not far from one of the entrances, in a moistened area (Fig. 25F). It was sheltered below a fragment of speleothem deeply buried in the cave floor. During the speleothem displacement, lots of sediment was turned, what may have caused the specimen's flagellum to detach. This area may be flooded during strong rains, but can also be dry in the peak of the dry seasons (although the exact place where the specimen was found is always moistened, even in the peak of the dry periods). As previously mentioned, several visits to the cave failed in finding additional specimens, even considering that all moistened habitats in other parts of the cave were also inspected, which indicates the rarity of this species. Furthermore, although it shares some common morphological traits with $A$. canhembora sp. nov., the harsh environmental conditions in the region are likely to prevent palpigrades from migrating between the two caves. The limestones from the Caatinga Formation are 'thin', rarely exceeding 20 meters in thickness. Considering the high aridity of the region, it is unlikely that suitable microhabitats would be kept along the whole extension between the caves, in such a thin rock layer. The moist subterranean habitats associated with the Caatinga limestones probably occur in patches (as observed in the macrocaves occurring in the area - most of them extremely dry and presenting only a few patches of moist substrates) which prevents migration across long distances. A fact that corroborates this hypothesis is that the few troglobitic species found in the Toca dos Ossos Cave were never observed at the Toca do Gonçalo Cave (and vice versa), so both caves do not share any troglobitic species. 
The Toca dos Ossos Cave has been the target of intense impacts in the last decades. In addition to the uncontrolled visits to the cave, which is located close to the Ourolandia town, part of the limestone rock above the cave has been exploited over the last years (Fig. 25D). This mining has caused the transport of rock fragments to some parts of the cave, which were partially covered by them (Fig. 25E). Fortunately, the quarry above the cave has been interdicted, although the quarrying still occurs in other surrounding areas. Furthermore, no restoration project is currently in progress, and considering that part of the rock (and consequently the epikarst) was removed, the hydrological dynamics of part of this system are presumably altered.

Thus, we would like to highlight the species' rarity and the degree of threats to which Allokoenenia sp. is subject. According to the current national speleological laws, caves can be destroyed, and the conservation is only ensured to those considered to be of maximum relevance. Among the criteria for classifying a cave in this category, is the presence of a rare, endemic or relict troglobitic species, and Allokoenenia sp. certainly fits in all these attributes. Hence, the record of this species directly contributes to the conservation of its habitat.

\section{Discussion}

About half of the Palpigradi species are cave dwellers and many of them have morphological adaptations that indicate an evolution associated with hypogean habitats. With the exception of Triadokoenenia Condé, 1991, a monotypic genus known solely from a rainforest of Madagascar, all other genera of Palpigradi have already been recorded in caves (Condé 1998). The records of Allokoenenia were somewhat doubtful, as the two immature specimens found in Thai caves referred as possibly belonging to this genus were not formally described by Condé (1992). Thus, the new species herein described confirm the presence of this genus in caves. As Eukoenenia is the most diverse genus, including edaphic and troglobitic species, the troglomorphisms esblished for Palpigradi are based on the morphological adaptations shown in representatives of this taxon (Condé 1998).

Although the original description of $A$. afra includes only the measurements of body size ( $1 \mathrm{~mm})$, first pair of legs $(0.60 \mathrm{~mm})$ and flagellum $(0.28 \mathrm{~mm})$, the study of the type material allowed us to take measurements of some articles of the palp and legs, as well as of the flagellar segments, provided in Tables 1-2. Considering the ratios proposed by Condé $(1996,1998)$ as indicative of appendage elongation (B/IVbta and IVbta/ti), the new species of Allokoenenia herein described present values similar to those of the troglobitic Eukoenenia $(B / I V b t a=1.94-2.21 ;$ IVbta/ti=0.91-0.99). At the same time, A. afra presents the value of the ratio $I V b t a / t i(0.70)$ similar to those of the edaphic species. It was not possible to obtain the value of the ratio B/IVbta for this species because the contour of the propeltidium was not interpretable. It is also noteworthy that the articles of the palp and of the legs I and IV of the three species herein described are longer than those of $A$. afra. This difference in length is particularly noticeable in leg I, in which the measured articles of $A$. afra, with the exception of tarsus 3 , have half or one third of the length when compared with those of $A$. canhembora sp. nov., A. stygia sp. nov., and Allokoenenia sp. $(t i=60$ vs $125-162 ; b t a l+2=55$ vs $112-137 ;$ bta $3=22$ vs $70-87 ; b t a 4=22$ vs $52-75 ;$ ta $1=12$ vs $30-35$; ta $2=20$ vs 40-47), as also observed in the tibia (67 vs 137-162) and basitarsus (47 vs 125-157) of leg IV. Therefore, the Brazilian species have more elongated appendages when compared to $A$. afra.

They also have more blades on lateral organs when compared to $A$. afra. While the African species has a single blade (Silvestri 1913), A. stygia sp. nov., Allokoenenia sp., and A. canhembora sp. nov. carry three, four, and five blades, respectively. The presence of three and four blades is a common characteristic in both soil and cave-adapted palpigrades (e.g., Christian \& Christophoryová 2013; Christian et al. 2014; Souza \& Ferreira 2019). However, as the number of blades often increases in the course of development, it is possible that the adults of Allokoenenia sp. have more numerous blades. The presence of five blades, 
observed in A. canhembora sp. nov., is a widespread feature in troglobitic species (e.g., Condé 1989; Barranco \& Mayoral 2014; Souza \& Ferreira 2016, 2018, 2020).

In addition to presenting troglomorphic traits, Allokoenenia sp. and A. canhembora sp. nov. inhabit caves located in a xeric region of Brazil, which provides further evidence that their populations are restricted to the subterranean biotopes.

Allokoenenia canhembora sp. nov. and Allokoenenia sp. are the first troglobitic palpigrades from the Caatinga Biome, Northeastern Brazil. Allokoenenia stygia sp. nov. comprises the first troglobitic species of the diverse and poorly studied palpigrade fauna from the Brazilian Amazon Forest, Northern Brazil, which was formally represented only by Leptokoenenia pelada Souza \& Ferreira, 2013, L. thalassophobica Souza \& Ferreira, 2013, and Eukoenenia janetscheki Condé, 1993. They are endemic to a single or few caves extremely threatened by anthropic activities, mainly mining and groundwater exploitation. Consequently, they are very vulnerable to extinction. Their formal descriptions are of utmost importance for the preservation of their habitats, since caves with rare troglobitic species are protected by the Brazilian law. Furthermore, this study represents a substantial improvement in the knowledge of the morphology and distribution of the genus Allokoenenia, now formally represented by three species distributed in the Afro and Neotropics.

\section{Acknowledgments}

We are grateful to Bruno Espinosa for providing access to the type specimens of Allokoenenia afra housed at the Entomological Museum Filippo Silvestri (Department of Entomology and Agricultural Zoology of the University of Naples Federico II, Italy) and Dr Peter Schwendinger (Department of Arthropodes and Entomology I, Natural History Museum of Geneva) for helping with this loan process and for allowing the use of the microscope and facilities of the department to study these specimens. We also thank Dr Ricardo Pinto da Rocha for sending specimens deposited in the collection of the Zoology Museum of São Paulo University (MZUSP) to be studied and described, Thadeu Pietrobon (Vale S.A.) for sending information and photos of the caves SB_0114 and SB_0112, Daniel Menin for the pictures of Toca dos Ossos Cave, and Grupo Bambuí de Pesquisas Espeleológicas for proving the plan view of this cave. Our gratitude also extends to the whole team of the Center of Studies in Subterranean Biology from the Federal University of Lavras (CEBS/UFLA) for their help in the field trips and to both referees for improvement of the manuscript. Finally, we thank FAPEMIG/Vale Co. (FAPEMIG grant $\mathrm{n}$. CRA RDP 00099/18) for fellowship and financial support; RLF also thanks the Conselho Nacional de Desenvolvimento Científico e Tecnológico (CNPq grant n. 308334/2018-3).

\section{References}

Ballesteros J.A., Santibáñez López C.E., Kováč Ĺ., Gavish-Regev E. \& Sharma P.P. 2019. Ordered phylogenomic subsampling enables diagnosis of systematic errors in the placement of the enigmatic arachnid order Palpigradi. Proceedings of the Royal Society B 286: 20192426. https://doi.org/10.1098/rspb.2019.2426

Barranco P. \& Mayoral J.G. 2014. New palpigrades (Arachnida, Eukoeneniidae) from the Iberian Peninsula. Zootaxa 3826: 544-562. https://doi.org/10.11646/zootaxa.3826.3.6

Bu Y., Souza M.F.V.R. \& Mayoral, J. 2021. Discovery of the genus Eukoenenia (Palpigradi: Eukoeneniidae) from China and description of a new species. Journal of Arachnology 49: 225-234. https://doi.org/10.1636/JoA-S-20-058

Christian E. \& Christophoryová J. 2013. Eukoenenia florenciae (Arachnida: Palpigradi): lessons from a newcomer to central Europe and the island of Tenerife. Biologia 68: 1182-1188. https://doi.org/10.2478/s11756-013-0266-3 
Christian E., Kováč L., Ozimec R., Polak S. \& Zagmajster M. 2012. Distribution and morphology of the European Karst palpigrade Eukoenenia gasparoi (Arachnida: Palpigradi). Journal of Arachnology 40: 265-273. https://doi.org/10.1636/Ha12-27.1

Christian E., Isaia M., Paschetta M. \& Bruckner A. 2014. Differentiation among cave populations of the Eukoenenia spelaea species-complex (Arachnida: Palpigradi) in the southwestern Alps. Zootaxa 3794: 52-86. https://doi.org/10.11646/zootaxa.3794.1.2

Condé B. 1977. Nouveaux palpigrades du muséum de Genève. Revue suisse de Zoologie 84: 665-674. https://doi.org/10.5962/bhl.part.91415

Condé B. 1984. Palpigrades (Arachnida) d'Europe, des Antilles, du Paraguay et de Thaïlande. Revue suisse de Zoologie 91: 369-392. https://doi.org/10.5962/bhl.part.81884

Condé B. 1989. Palpigrades (Arachnida) de grottes d'Europe. Revue suisse de Zoologie 96: 823-840. https://doi.org/10.5962/bhl.part.82064

Condé B. 1992. Un Palpigrade énigmatique de Thaïlande avec une brève revue des grandes divisions de l'ordre. Revue suisse de Zoologie 99: 741-746. https://doi.org/10.5962/bhl.part.79850

Condé B. 1996. Les Palpigrades, 1885-1995: acquisitions et lacunes. Revue suisse de Zoologie hors série 1: 87-106.

Condé B. 1998. Palpigradida. In: Juberthie C. \& Decu V. (eds) Encyclopaedia Biospeologica. Vol. 2: 913-920. Société de Biospéologie, Moulis, Bucharest.

Culver D.C. \& Sket B. 2000. Hotspots of subterranean biodiversity in caves and wells. Journal of Cave and Karst Studies 62: 11-17.

Giribet G., McIntyre E., Christian E., Espinasa L., Ferreira R.L., Francke O.F., Harvey M.S., Isaia M., Kováč Ĺ., Mc-Cutchen L., Souza M.F.V.R. \& Zagmajster M. 2014. The first phylogenetic analysis of Palpigradi (Arachnida) - the most enigmatic arthropod order. Invertebrate Systematics 28: 350-360. https://doi.org/10.1071/IS13057

Harvey M.S. 2002. The neglected cousins: what do we know about the smaller arachnid orders? The Journal of Arachnology 30: 357-372.

https://doi.org/10.1636/0161-8202(2002)030[0357:TNCWDW]2.0.CO;2

Harvey M.S. 2003. Catalogue of the Smaller Arachnid Orders of the World: Amblypygi, Uropygi, Schizomida, Palpigradi, Ricinulei and Solifugae. CSIRO Publishing, Melbourne. https://doi.org/10.1071/9780643090071

Mayoral J.G. \& Barranco P. 2013. Rediscovery of the troglobious palpigrade Eukoenenia draco (Peyerimhoff 1906) (Palpigradi: Eukoeneniidae), with notes on the adaptations to a cave-dwelling life. Zootaxa 3635: 174-184. https://doi.org/10.11646/zootaxa.3635.2.5

Mayoral J.G. \& Barranco P. 2017. A cave-dwelling Iberian palpigrade (Arachnida: Palpigradi) of the Eukoenenia mirabilis group. Zootaxa 4363: 561-568. https://doi.org/10.11646/zootaxa.4363.4.8

Prevorčnik S., Ferreira R.L. \& Sket B. 2012. Brasileirinidae, a new isopod family (Crustacea: Isopoda) from the cave in Bahia (Brazil) with a discussion on its taxonomic position. Zootaxa 3452: 47-65. https://doi.org/10.11646/zootaxa.3452.1.2

Rowland J.M. \& Sissom W.D. 1980. Report on a fossil palpigrade from the Tertiary of Arizona, and a review of the morphology and systematics of the order (Arachnida). The Journal of Arachnology 8: 69-86.

Silvestri F. 1913. Novi generi e specie de Koeneniidae (Arachnida, Palpigradi). Bollettino di Laboratorio di Entomologia Agraria Portici 7: 211-217. 
Souza M.F.V.R. \& Ferreira R.L. 2013. Two new species of the enigmatic Leptokoenenia (Eukoeneniidae: Palpigradi) from Brazil: first record of the genus outside intertidal environments. PLoS ONE 8: e77840. https://doi.org/10.1371/journal.pone.0077840

Souza M.F.V.R. \& Ferreira R.L. 2016. Two new troglobiotic palpigrades (Palpigradi: Eukoeneniidae) from Brazil. Zootaxa 4171: 246-258. https://doi.org/10.11646/zootaxa.4171.2.2

Souza M.F.V.R. \& Ferreira R.L. 2018. Pandora is on Earth: new species of Eukoenenia (Palpigradi) emerging at risk of extinction. Invertebrate Systematics 32: 581-604. https://doi.org/10.1071/IS17049

Souza M.F.V.R. \& Ferreira R.L. 2019. Eukoenenia igrejinha (Palpigradi: Eukoeneniidae), a new cave-dwelling palpigrade from southeastern Brazil. The Journal of Arachnology 47: 360-369. https://doi.org/10.1636/0161-8202-47.3.360

Souza M.F.V.R. \& Ferreira R.L. 2020. Three new cave-dwelling Eukoenenia (Palpigradi: Eukoeneniidae) from limestone caves in Northern Minas Gerais state, Brazil. Zootaxa 4808: 251-283. https://doi.org/10.11646/zootaxa.4808.2.2

Souza M.F.V.R., Mayoral J. \& Ferreira R.L. 2020. A new troglobitic palpigrade from Central Brazil, with notes on a new opisthosomal character (Arachnida: Palpigradi). Zootaxa 4869: 493-514. https://doi.org/10.11646/zootaxa.4869.4.2

Souza-Silva M. \& Ferreira R.L. 2016. The first two hotspots of subterranean biodiversity in South America. Subterranean Biology 19: 1-21. https://doi.org/10.3897/subtbiol.19.8207

Manuscript received: 30 May 2021

Manuscript accepted: 24 November 2021

Published on: 24 January 2022

Topic editor: Fabio Cianferoni

Section editor: Rudy Jocqué

Desk editor: Eva-Maria Levermann

Printed versions of all papers are also deposited in the libraries of the institutes that are members of the EJT consortium: Muséum national d'histoire naturelle, Paris, France; Meise Botanic Garden, Belgium; Royal Museum for Central Africa, Tervuren, Belgium; Royal Belgian Institute of Natural Sciences, Brussels, Belgium; Natural History Museum of Denmark, Copenhagen, Denmark; Naturalis Biodiversity Center, Leiden, the Netherlands; Museo Nacional de Ciencias Naturales-CSIC, Madrid, Spain; Real Jardín Botánico de Madrid CSIC, Spain; Zoological Research Museum Alexander Koenig, Bonn, Germany; National Museum, Prague, Czech Republic. 